\title{
The Impact of Informational and Emotional Television Ad Content on Online Search and Sales
}

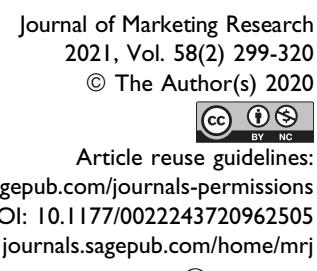

(SAGE

\author{
Ivan A. Guitart and Stefan Stremersch
}

\begin{abstract}
This article documents how informational and emotional appeals in more than 2,000 television ads for I44 car models, aired over four years, influence online search and sales. Increasing the emotional content of ads leads to increases in online search, but increasing the informational content does not. Both informational and emotional content positively influence sales. However, increases in informational content lead to more incremental sales for low-price and low-quality cars than for high-price and highquality cars. In turn, increases in emotional content generate more incremental sales for high-price cars than for low-price cars. Analyses of the results suggest that managers of high-price and high-quality cars should prioritize emotional rather than informational content in ads. However, managers of low-price and low-quality cars should emphasize emotional content if their objective is to increase online search and informational content if their objective is to increase sales.
\end{abstract}

\section{Keywords}

advertising content, advertising effectiveness, automotive industry, online search, purchase funnel, television advertising

Online supplement: https://doi.org/I0.I I 77/0022243720962505

Television is one of the most preferred media for advertisers, with spending forecasts rising to $\$ 172.9$ billion worldwide in 2021 (Statista 2020a). Given the relevance of television advertising, managers must understand which ad content will be more effective for achieving their communication objectives. Generally, these objectives involve moving consumers along the purchase funnel (Batra and Keller 2016). Although recent literature has studied the impact of television advertising spending across different stages of this funnel (e.g., Hu, Du, and Damangir 2014; Joo et al. 2014), the literature has paid limited attention to how ad content influences ad effectiveness across the different stages.

In this article, we study how ad content influences ad effectiveness at generating online search and sales, two important stages of the purchase funnel. We classify ad content into informational and emotional content, because this classification is often used by practitioners and researchers (Chandy et al. 2001; Heath and Stipp 2011; Thompson 2011). Furthermore, we study how the effects of informational and emotional content are contingent on product positioning, operationalized through price and quality (Lemon and Nowlis 2002; Nowlis and Simonson 1996). ${ }^{1}$

\footnotetext{
${ }^{1}$ Several studies refer to low, and even negative, correlations between price and quality across industries (Tellis and Wernerfelt 1987). Therefore, we consider price and quality as two different dimensions of positioning.
}

We put together a novel, comprehensive data set from the car industry that includes new car registrations, volume of online search, advertising spending and content, product quality ratings, and product attributes. The advertising content data covers 2,317 television ads that ran from January 2007 through September 2010, representing a total of $\$ 11.3$ billion in spending for 144 car models. We collected quality ratings from major automotive websites, online search data from Google Trends, and data on car prices and attributes from Wards Auto. In modeling online search and sales, we account for the carryovers of advertising and online search and for the potential endogeneity of advertising spending, ad content, price, and online search. Furthermore, we decompose the impact of advertising on sales into a direct impact and an indirect impact through online search.

We find that ads high in emotional content generate more online search than ads low in emotional content, regardless of the price or quality of the car. However, the amount of informational content does not seem to influence online search. We also find that increases in informational content generate more

Ivan A. Guitart is Associate Professor, Emlyon Business School, France (email: guitart@em-lyon.com). Stefan Stremersch is Desiderius Erasmus Distinguished Chair of Economics and Chair in Marketing, Erasmus School of Economics, Erasmus University Rotterdam, the Netherlands; and Visiting Professor, IESE Business School, University of Navarra, Spain (email: stremersch@ese.eur.nl). 
incremental sales for low-price and low-quality cars than for high-price and high-quality cars. Furthermore, increases in emotional content generate more incremental sales for highprice cars than for low-price cars. In addition, we find that the impact of online search on sales is stronger for low-price than for high-price cars. For instance, a 10\% increase in the volume of online search leads to a $3.6 \%$ increase in sales for a $\$ 15,000$ car but generates no significant change in sales for a $\$ 60,000$ car. Accordingly, the indirect impact of advertising on sales (through online search) is stronger for low-price than for highprice cars, suggesting that using advertising to encourage consumers to search online is more valuable for cars with lower prices. Finally, we find that adding ad content and online search as covariates in a sales model improves its in- and out-ofsample performance.

These findings advance the marketing literature in three ways. First, a few studies examine the effects of ad content on consumers' behavioral responses such as online search or sales (e.g., Bass et al. 2007; Becker, Wiegand, and Reinartz 2019; Chandy et al. 2001; Du, Xu, and Wilbur 2019). These studies have not explored if and how the effects of ad content vary across products with different positioning. Thus, for managers it is not clear how to manage ad content to increase the effectiveness of their ads given the specific position that their products have in the market. This study addresses this gap.

Second, we study the impact of product online search on product sales and explore how this relationship depends on the positioning of the product. This knowledge can inform managers about the extent to which their efforts to increase online search affect sales and how this impact depends on the positioning of the products they manage. The insights we add to the literature are that advertising indirectly influences sales though its effect on online search, that this indirect effect is higher for products with a low price than for products with a high price, and that not accounting for this indirect effect in a panel data model for sales biases the estimates of advertising elasticity.

Third, prior research has studied the impact of ad content on either online search (Chandrasekaran, Srinivasan, and Sihi 2018; Du, Xu, and Wilbur 2019) or sales (Chandy et al. 2001; Gopinath, Thomas, and Krishnamurthi 2014) but not both at the same time. Our study is the first to quantify the impact of informational and emotional ad content on online search and sales concurrently, which is critical to understand how the impact of ad content materializes across funnel stages. This knowledge informs decisions on ad content, tailored to specific managerial objectives (i.e., increase online search or sales).

In terms of managerial implications, our results imply that managers of high-price and high-quality cars should prioritize emotional content rather than informational content in their ads. However, managers of low-price and low-quality cars should use ads with high levels of emotional content if their objective is to increase online search and ads with high levels of informational content if their objective is to increase sales. Finally, our results suggest that including online search and advertising content in sales models can help analysts generate better sales forecasts and obtain more accurate advertising elasticities.

\section{Related Literature}

This article builds on two prior literature streams: the first studies the relationships between television advertising, online search, and sales, and the second studies advertising content. We review these literature streams in the following subsections.

\section{Television Advertising, Online Search, and Sales}

Consumers search to reduce their uncertainty before purchasing a product (Moorthy, Ratchford, and Talukdar 1997; Murray 1991). Exposure to product information during the search stage can alter their beliefs, attitudes, and knowledge (Edelman 2010). Consumers who learn about the product tend to purchase more frequently and become more profitable (Chan, $\mathrm{Wu}$, and Xie 2011). Even if the search does not immediately lead to a sale, it can have indirect benefits, such as increased word of mouth (Bloch, Sherrell, and Ridgway 1986). Therefore, encouraging consumers to engage in product information search is an important managerial goal, because it can lead to improvements in firm profitability.

The literature also suggests that online search is important because it can help managers better predict product sales. For instance, Choi and Varian (2012) show that online search data helps predict aggregated sales in the form of general economic indicators. In addition, $\mathrm{Hu}, \mathrm{Du}$, and Damangir (2014) demonstrate that latent constructs derived from product online search data increase the predictive accuracy of a sales model. In this article, we document the magnitude of the online search-sales relationship and study how this relationship changes according to the positioning of the product.

Prior studies have demonstrated that managers can use television advertising to increase online search. Advertising can generate interest in the product and encourage consumers to search online to complement information delivered in the ads (Mayzlin and Shin 2011). Recent empirical investigations have noted the relationship between television advertising and the propensity of consumers to seek out product information on the internet. For example, Zigmond and Stipp (2010) find that television ads lead to an immediate increase in consumers' online search activity. Joo et al. (2014) and Joo, Wilbur, and Zhu (2016) indicate that television advertising increases the likelihood that consumers will use branded keywords in their online search. In addition, Dinner, Van Heerde, and Neslin (2014) offer evidence that offline advertising has a positive, significant impact on the number of search impressions.

\section{Advertising Content Studies}

Studies in advertising content have a long tradition in marketing. Some studies have considered a large number of different cues. For instance, Stewart and Furse (1986) analyze the 
effectiveness of 25 executional factors and find that the ads that emphasize the main differentiator of the product and contain a strong product focus exert the strongest effects on recall, comprehension, and persuasion. Stewart and Koslow (1989) analyze a different set of ads and replicate the findings in Stewart and Furse (1986). Hartnett et al. (2016) also replicate Stewart and Furse's study using sales effectiveness as the dependent variable. They find that psychological benefits, humorous tones, no principal characters, and negative appeals correlate positively with sales. Bruce, Becker, and Reinartz (2020) consider 17 cues often used in ads and find that the primary drivers of ad effectiveness are visual salience cues.

Other studies have focused on a narrower set of content, generally emphasizing the distinction between informational and emotional content, which is in line with the idea that attitudes toward the ad are driven by cognitive and affective evaluations of the ad (Batra and Ray 1985; Muehling and McCann 1993). For instance, MacInnis, Rao, and Weiss (2002) study informational, heuristic, and affective cues in advertising and find that the affective cues, especially those that evoke positive feelings, are the most effective for influencing sales. Bass et al. (2007) and Bruce (2008) examine the effects of different advertising themes on the sales of a telecommunications service company and find that informational ads tend to wear out faster than emotional ones. Bertrand et al. (2010) assess consumer responses to direct mail advertising and discern that advertising content persuades by appealing to intuition rather than to reason. Geuens, De Pelsmacker, and Faseur (2011) find that emotional ads outperform nonemotional ones in terms of attitude toward the ad and the brand. Chandrasekaran, Srinivasan, and Sihi (2018) study lifts in online search after Super Bowl ads and find that informational content leads to an increase in search, whereas emotional content does not generate such lift.

Prior research has also established boundary conditions to understand when different ad content works better. Chandy et al. (2001) find that argument-focused appeals are more effective in young markets than in old markets, whereas emotional appeals are more effective in old markets than in young markets. Pham, Geuens, and De Pelsmacker (2013) report that adevoked feelings have a substantial positive impact on brand evaluations, especially for hedonic products. Gopinath, Thomas, and Krishnamurthi (2014) find that emotion-based ads have a greater impact on sales than attribute-based ads, but the effectiveness of both ad types decreases over the product life cycle. Kopalle et al. (2017) find that advertising about quality positively affects sales of high-quality but not low-quality brands.

Advertising content may also affect outcomes differentially across the purchase funnel. For example, Liaukonyte, Teixeira, and Wilbur (2015) find that action-focused content increases website traffic and purchases, whereas imagery-focused content reduces website traffic; information- and emotion-focused content both reduce website traffic but increase online purchases. Du, Xu, and Wilbur (2019) find that ads that are more informative, likable, or desirable lead to more immediate brand searches but not necessarily to more online price quote requests. In Table 1 , we show an overview of prior studies on advertising content and articulate our contribution to this literature.

\section{Conceptual Framework}

Advertising theory suggests that advertising works due to its informative and persuasive effects (Ackerberg 2001; Mehta, Chen, and Narasimhan 2008). Advertising has an informative effect because it provides product information that reduces consumers' uncertainty about the true quality of the product. Advertising has a persuasive effect because it creates image associations that imbue social meaning and affective value into the product. The informative effect of advertising is enabled by informational content, defined as content that stresses factual information or the utilitarian consequences of product use (Bagozzi, Gopinath, and Nyer 1999; Puto and Wells 1984). The persuasive effect of advertising is enabled by emotional content, defined as content that either elicits emotions or conveys unprovable value-expressive and hedonic benefits that consumers will experience through the ownership or use of the product (Bagozzi, Gopinath, and Nyer 1999; Puto and Wells 1984).

We propose that the effects of informational and emotional content will depend on the positioning of products. Prior research has shown that positioning moderates the impact of marketing-mix variables. For instance, Bronnenberg and Wathieu (1996) find that price promotions are more effective for high-tier than low-tier brands, whereas Lemon and Nowlis (2002) show that positioning also moderates the impact of displays and feature advertising. We operationalize positioning using the price and quality of a product for three reasons. First, price and quality are commonly used as a basis for positioning strategies (Aaker and Shansby 1982; Hooley, Broderick, and Moller 1998). Second, prior research has shown that many markets - including the automotive market, which is the focus of our empirical application - contain brands differentiated in terms of price and quality (Lemon and Nowlis 2002; Nowlis and Simonson 1996). Third, in line with our empirical application, the largest review websites in the automotive industry (e.g., U.S. News, J.D. Power, Edmunds) generally emphasize these variables because they are important for consumers and provide a common point of comparison across products.

We integrate the role of ad content and positioning in a framework relating advertising spending, online search, and sales (Figure 1). We propose that advertising spending directly affects online search and sales. The effects of advertising spending on online search and sales are moderated by advertising content. In turn, the effects of advertising content depend on the positioning of the product. We also propose that online search affects product sales (and thus that advertising has an indirect effect on sales through online search) and that this impact is contingent on product positioning. Next, we provide a rationale for the relationships we propose in the theoretical framework. Table 2 presents a summary of our expectations together with our empirical findings. 


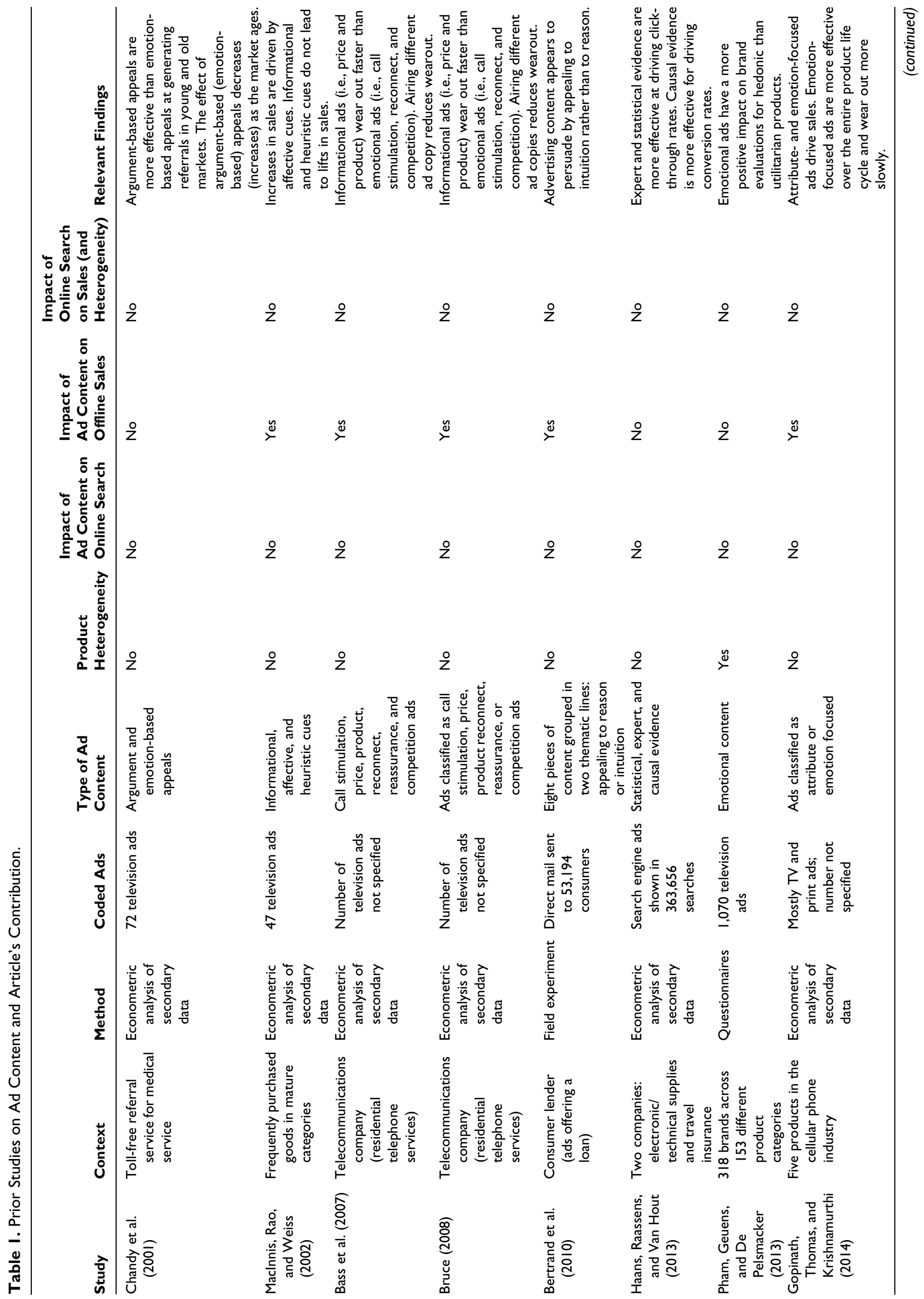




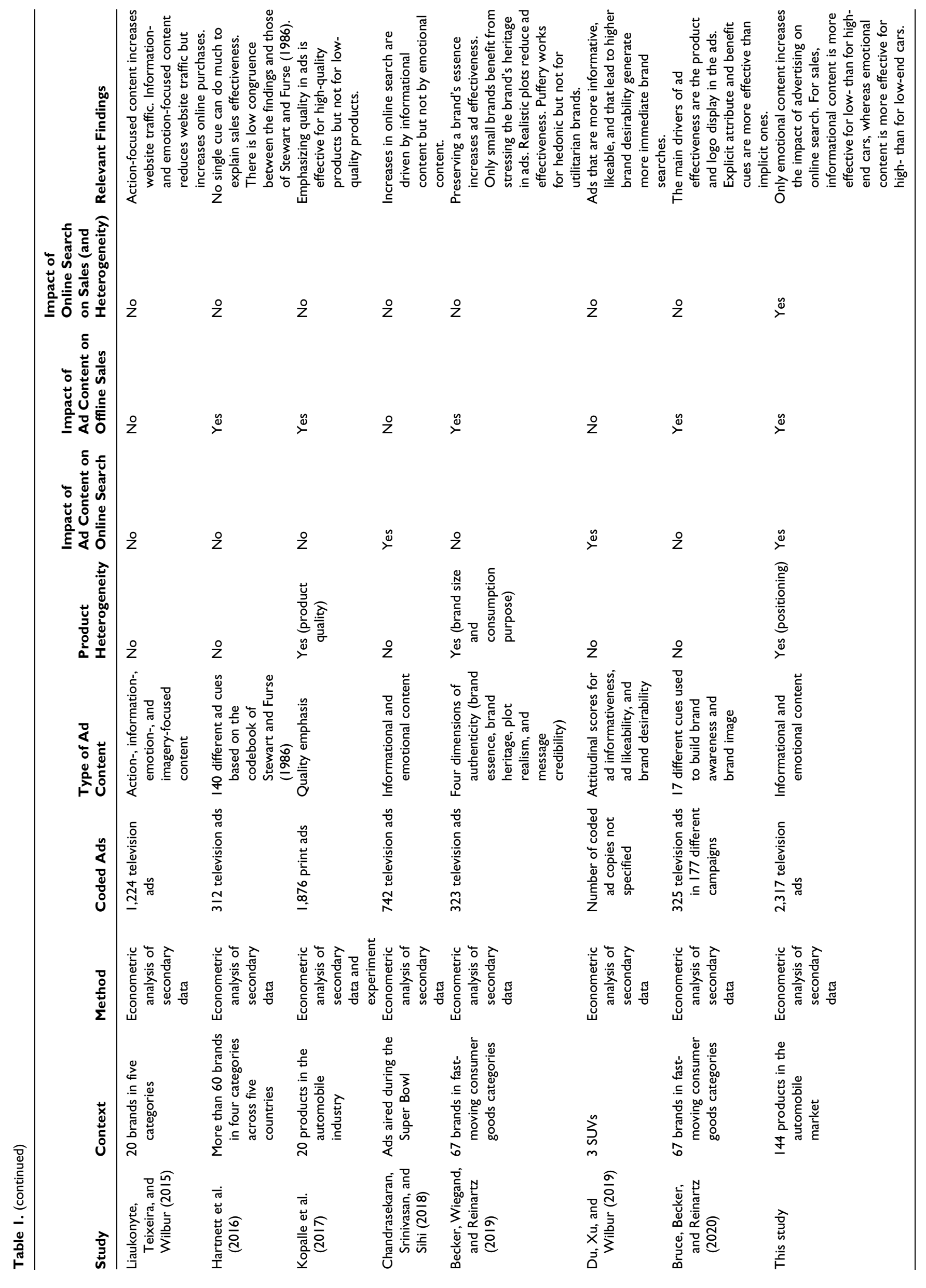




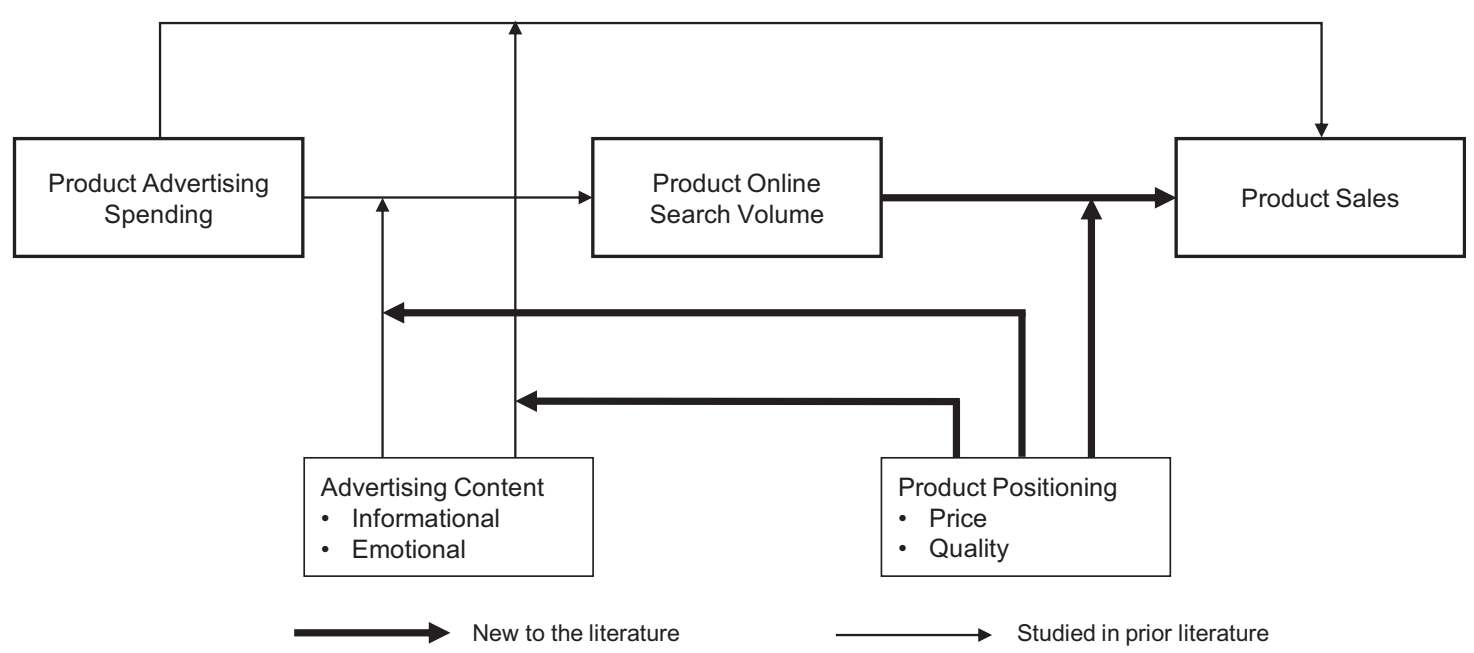

Figure I. Conceptual framework.

Table 2. Summary of Expectations and Findings.

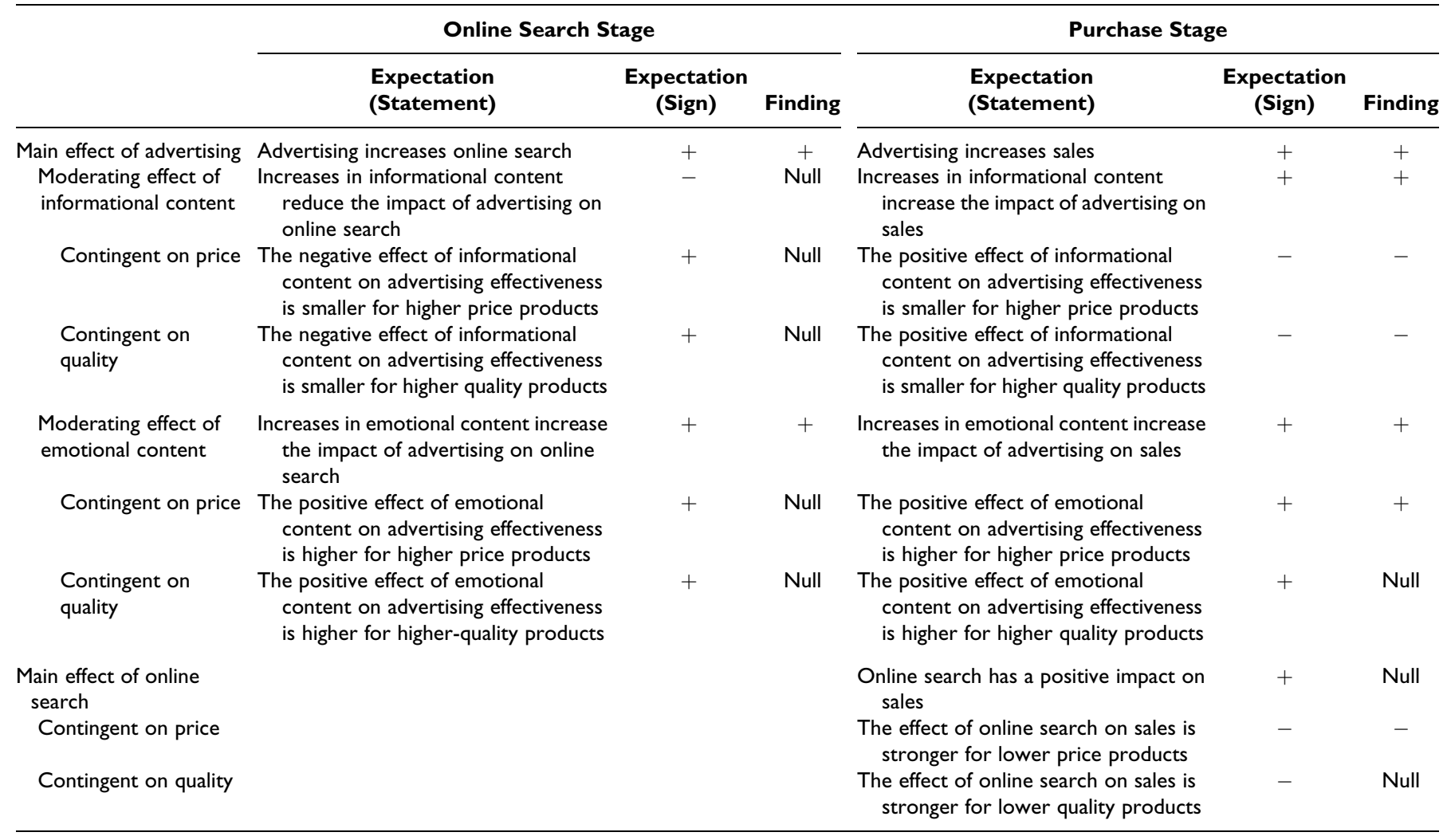

\section{Effect of Advertising Spending on Online Search}

In the conceptual framework, we propose that advertising spending directly affects online search. As previously mentioned, advertising informs consumers about the quality of the product. This information, in turn, should reduce consumers' uncertainty about product quality and thus their need to search for additional product information. According to this logic, advertising should reduce online search. However, advertising can also generate interest in the product because it can elicit feelings that increase the product's value. According to this reasoning, advertising should increase online search. Although we cannot assess a priori which of these effects dominates, prior research has found a positive association between advertising and online search (Dinner, Van Heerde, and Neslin 2014; 
Joo et al. 2014; Joo, Wilbur, and Zhu 2016). Therefore, we expect to find a positive association between advertising and online search.

We expect increases in informational content to reduce the positive impact of advertising on online search. Consumers search to reduce their uncertainty about product quality (Moorthy, Ratchford, and Talukdar 1997; Murray 1991). This uncertainty refers to the probability that the quality of the product will be lower than expected (Kalish 1985). Increases in the informational content of advertising provide additional product knowledge, which should reduce consumers' uncertainty, the need for more information to solve this uncertainty, and thus the likelihood of searching online (Anderson and Renault 2006; Mayzlin and Shin 2011).

We expect the uncertainty reduction effect of informational content in advertising to be higher for low-price and lowquality products than for high-price and high-quality products. Consumers' uncertainty should be lower for high-quality than for low-quality products because high-quality products are generally manufactured with stricter conformance quality requirements (Wu 2010). Moreover, uncertainty should be lower for high-price products because consumers are more likely to use price as a signal of quality for expensive products (Olson 1977). Because the uncertainty reduction effect of information is higher when uncertainty is higher, we expect the negative effect of informational content on advertising effectiveness to be larger for low-price and low-quality products than for highprice and high-quality products.

We expect increases in emotional content to increase the positive impact of advertising on online search. By definition, emotional content elicits emotions and emphasizes the valueexpressive and hedonic benefits that consumers may get from owning and using the product. Emotional content can generate positive feelings among consumers about the product (Pham, Geuens, and De Pelsmacker 2013), which, in turn, may increase consumer interest and, thus, online search.

We expect the effect of emotional content to be higher for high-price and high-quality products than for low-price and low-quality products. Emotions in ad content are more effective if the feelings they evoke are relevant for the evaluation of the product (Pham 1998). Compared with low-price products, consumers are more likely to evaluate high-price products on the basis of their value-expressiveness because these products are more successful at communicating cues such as social status and prestige (Amaldoss and Jain 2005). Compared with low-quality products, consumers are more likely to evaluate high-quality products on the basis of their hedonic value because these products generally possess better design and higher-quality components that make their use more pleasant and enjoyable. Therefore, the value-expressive and hedonic appeals in emotional content should be more relevant and, thus, more effective at generating interest and search for high-price and high-quality products than for low-price and low-quality products.

\section{Effect of Advertising Spending on Sales}

In the conceptual framework, we propose that advertising spending directly affects sales. In line with advertising theory, we expect advertising spending to have a positive effect on sales. Advertising leads to sales because it provides information that lowers uncertainty about the product and because it generates feelings that increase the value of the product.

We expect that increases in the amount of informational content will increase advertising effectiveness at the purchase stage. As we have argued, the higher the amount of information, the higher the reduction in uncertainty, and the higher the informational effect of advertising. Moreover, we expect the informational effect of informational content to be smaller (i.e., less positive) for high-price and high-quality products than for low-price and low-quality products. The uncertainty associated with high-price and high-quality products is lower, so the uncertainty reduction effects of informational content should be smaller for these products than for low-price and low-quality products.

We expect increases in emotional content to strengthen the persuasive effects of advertising and to lead to higher sales because the positive feelings aroused by emotional content can be incorporated into summary product evaluations and increase the value of the product (Pham 1998, 2004). We also expect the persuasive effect of emotional content to be higher for highprice and high-quality products (compared with low-price and low-quality products). As we have mentioned, feelings are more effective at changing product evaluations when they are relevant for such evaluations (Pham 1998). Moreover, valueexpressive and hedonic benefits are more relevant for the evaluation of high-price and high-quality products. Therefore, the feelings aroused by the value-expressive and hedonic appeals used in emotional content should be more effective for highprice and high-quality products than for low-price and lowquality products.

In summary, our theorizing predicts different effects of informative content at the online search and purchase stages. Informative content reduces uncertainty about the product, which reduces the need for online search but increases sales. The negative (positive) effect of informative content on online search (sales) should be smaller for high-price and high-quality products because uncertainty is already small for these products (compared with low-price and low-quality products). In addition, our theorizing predicts the same effects of emotional content at the online search and purchase stages. Emotional content creates image associations that generate interest (online search) and lead to more sales. The persuasive effect on both search and sales should be stronger for high-price and highquality products than for low-price and low-quality products. The reason is that the feelings evoked by value-expressive and hedonic content are more relevant for the evaluation of highprice and high-quality products than for low-price and lowquality products. 


\section{Effect of Online Search on Sales}

Information search allows consumers to learn and reduce their uncertainty about the product (Murray 1991), which increases consumer preference for the product (Rust et al. 1999) and, thus, sales. We expect the effect of online search on sales to be stronger for low-price and low-quality products than for high-price and high-quality products. First, the uncertainty reduction effects of online search should be larger for low-price and low-quality products because uncertainty is larger for these products than for high-price and high-quality products. Second, given the marked valueexpressive and hedonic benefits of high-price and highquality products, they are likely to attract the attention of a large number of consumers who may not be in the market for the product but are interested in knowing more about it (e.g., recreational search). For instance, in the automotive market, such recreational search is common for brands such as Ferrari or Porsche or products such as the Ford Mustang or the BMW M3. This implies that the rate at which searches convert into sales should be smaller for highprice and high-quality products than for low-price and low-quality products.

\section{Research Context and Data}

The research context for our study is the U.S. automotive market. This market is an appropriate setting for our study for several reasons. First, it is important in the broader economy, which increases the relevance of our study. Car manufacturers and their suppliers generated approximately $\$ 752$ billion in 2018 (Statista 2020b) and are responsible for approximately $3 \%$ of the U.S. gross domestic product (American Auto Council 2018). Second, automobiles are complex products, so information search is an important part of their purchase funnel. According to a recent study (Gustafson 2018), $88 \%$ of new car buyers used the internet to find information about cars in 2017. Third, car manufacturers spend substantial amounts on television advertising, with a wide variety of content. This variation provides a good empirical setting in which to study the effect of informational and emotional ad content on online search and sales. Fourth, the wide variety of car models enables us to study heterogeneity in advertising effectiveness.

\section{Sales}

We obtained monthly information about car registrations at the car model level from January 1996 to October 2010 from R.L. Polk \& Company. We identified a car model as the unique combination of parent brand (e.g., Toyota, Lexus), model name (e.g., Corolla, RX), and engine (hybrid/gasoline). Current U.S. legislation dictates that cars must be registered within 10-30 days of their purchase (with some variability across states), so the sale of a car occurred, at most, one month prior to its registration. To account for this potential delay in the registration associated with a purchase, we refer to registrations in month $t+1$ as sales in month $t$.

\section{Online Search}

We collected monthly online search indexes from Google Trends between January 2004 and October 2010, using a procedure similar to that described by $\mathrm{Hu}, \mathrm{Du}$, and Damangir (2014). We retrieved the search volumes using queries that contained the keywords for each brand, model, and engine. To exclude non-shopping-related searches, we used the following syntax for these queries: "brand + model - recall - parts - used - repair." We considered hybrid versions of a car model (e.g., Toyota Corolla Hybrid) as a different car model, so in these cases, we included "- hybrid" and "+ hybrid" in the syntaxes for the gasoline and the hybrid versions, respectively. ${ }^{2}$ We executed the queries with the "Autos \& Vehicles" category filter. We aggregated the queries at the monthly level for all the car models considered in the advertising content data set (described subsequently). Importantly, the structure of our queries implies that the retrieved search indexes are likely to capture searches intended to obtain product information. Searches aimed at obtaining purchase-related information (e.g., dealer information) are less likely to be captured by the indexes because consumers are likely to use queries with keywords such as "dealer" or "store."

In our model, we allowed for the possibility that the volume of online search may have a dynamic effect on sales because online searches in the previous months may affect consumers' purchase decisions in the current month. To account for the dynamic effects, we calculated an online search stock variable according to the following equation:

$$
\begin{aligned}
\text { OnlineSearchStock }_{\mathrm{jt}}= & \lambda_{1} \text { OnlineSearchStock }_{\mathrm{jt}-1} \\
& +\left(1-\lambda_{1}\right) \ln \left(\text { OnlineSearch }_{\mathrm{jt}}+1\right),
\end{aligned}
$$

where the parameter $\lambda_{1}\left(0 \leq \lambda_{1}<1\right)$ represents the carryover effect of online search, and OnlineSearch $\mathrm{j}_{\mathrm{j}}$ is the volume of online search for product $\mathrm{j}$ in month $\mathrm{t}$ (we add 1 to this variable to avoid undefined evaluations of the logarithmic function).

\section{Television Advertising Spending}

We obtained manufacturers' monthly television advertising spending at the product level from January 1996 to September 2010 from Kantar Media. We assessed the dynamic impact of advertising on online search and sales using an advertising stock variable $\left(\mathrm{AdStock}_{\mathrm{jt}}\right)$. We operationalized this variable for product $\mathrm{j}$ in month $\mathrm{t}$ as (Danaher and Van Heerde 2018; Dinner, Van Heerde, and Neslin 2014):

\footnotetext{
${ }^{2}$ During the observation period, the hybrid engine was perceived as a big innovation, and hybrid cars had an important price premium, so we considered a hybrid version as a different car model.
} 


$$
\text { AdStock }_{\mathrm{jt}}=\lambda_{2} \text { AdStock }_{\mathrm{jt}-1}+\left(1-\lambda_{2}\right) \ln \left(\mathrm{A}_{\mathrm{jt}}+1\right),
$$

where $A_{j t}$ is television advertising spending in dollars for product $\mathrm{j}$ in month $\mathrm{t}$. The parameter $\lambda_{2}\left(0 \leq \lambda_{2}<1\right)$ represents the advertising carryover effect. We allowed this carryover effect to differ for the advertising and the online search stocks. We initialized advertising stock using the product's ad spending during its introductory month. For products that were in the market before 1996, we initialized the stock using the ad spending in January 1996.

\section{Ad Content}

The advertising data set specifies spending for all individual ads broadcast on television; we complemented this information with videos of the ads, also obtained from Kantar Media, which we used to code the content of 2,342 ads broadcast from January 2007 to September 2010. To select these ads, we first considered vehicles in the sport utility vehicle (SUV) and sedan categories and focused on the ten best-selling brands in the premium (e.g., BMW, Mercedes Benz) and the ten best-selling brands in the nonpremium (e.g., Ford, Toyota) segments (we provide the list of brands in Web Appendix A). These vehicles account for $82.6 \%$ of total sales in the SUV and sedan categories. Next, we selected the ads with total spending of at least $\$ 1$ million during the 45 months under study, representing total expenditures of $\$ 11.3$ billion and $92 \%$ of the television advertising spending for the considered products.

To code the advertising content, we used an adapted version of Stewart and Furse's (1986) codebook, which we checked and refined several times before starting the coding task. The final version of the codebook describes an ad on 118 different items, as listed in Web Appendix B. Consistent with previous research (Bruce, Becker, and Reinartz 2020; MacInnis, Rao, and Weiss 2002), we recruited 12 university students (18-26 years of age) as coders, instructing them to evaluate ads solely on the basis of the stimuli present, not their previous experience (Stewart and Furse 1986). Before starting their task, the coders went through a learning period, in which they had to code 25 outof-sample ads to become familiar with the codebook and gain speed. We encouraged coders to ask questions during this period to clarify the meaning of any items in the codebook. For the coding of in-sample ads, which started after the coders had completed this calibration, we scheduled three sessions per week to accommodate their study schedules. To minimize fatigue, the sessions featured two 80minute blocks, with a 20 -minute break between blocks. This structure also allowed close control over the coding progress, because one of the authors could be present in the room for every session.

Furthermore, each advertisement was coded by two coders so that we could estimate intercoder agreement. We randomized the allocation and the coding order of commercials across coders. This random allocation also helped avoid the bias that might be generated by coders' familiarity with the codebook over time. The average per-item intercoder agreement was $.866(\mathrm{SD}=.011)$. Because we could not resolve coding disagreements by discussion, due to the large number of items being coded, we instead considered an item present if any coders indicated that status. This rule is in line with the reasoning that the probability of missing the presence of an item is much higher than the probability of reporting an item as present when it is not actually there.

We operationalized the ad content variables, Informatio$\mathrm{nal}_{\mathrm{jt}}$ and Emotional $_{\mathrm{j}}$, using the following procedure. For each ad $\mathrm{c}$, we created the variable $\operatorname{Info}_{\mathrm{c}}$ as the sum of items V1V25 in the codebook. All these items were labeled "informational content" in Stewart and Furse's (1986) original codebook because they provide information about the product and its use. In addition, we created the variable Emot $_{\mathrm{c}}$ by summing items V47-V73 in the codebook. These items refer primarily to the hedonic and value-expressive appeals included in the ad as well as to its capacity to trigger emotional responses. The operationalization of $\operatorname{Info}_{\mathrm{c}}$ and $\mathrm{Emot}_{\mathrm{c}}$ implies that that ads with more informational (emotional) cues are more informational (emotional). ${ }^{3}$ The correlation between Info $_{c}$ and Emot $_{c}$ is .01 $(p=.67)$, suggesting that the use of informational content does not necessarily imply absence of emotional content and vice versa.

Because there could be several advertisements per month for a specific car, we calculated the car-specific amount of informational (emotional) content in a month as the expenditure-weighted average number of informational (emotional) cues per commercial. Mathematically,

$$
\begin{aligned}
\text { Informational }_{\mathrm{jt}} & =\frac{\sum_{\mathrm{c}=1}^{\mathrm{C}_{\mathrm{jt}}} \text { Info }_{\mathrm{c}} \mathrm{AE}_{\mathrm{ct}}}{\sum_{\mathrm{ct}=1}^{\mathrm{C}_{\mathrm{jt}}} \mathrm{AE}_{\mathrm{ct}}}, \\
\text { Emotional }_{\mathrm{jt}} & =\frac{\sum_{\mathrm{c}=1}^{\mathrm{C}_{\mathrm{jt}}} \mathrm{Emot}_{\mathrm{c}} \mathrm{AE}_{\mathrm{ct}}}{\sum_{\mathrm{c}=1}^{\mathrm{C}_{\mathrm{j}}} \mathrm{AE}_{\mathrm{ct}}},
\end{aligned}
$$

where $C_{j t}$ is the total number of commercials for product $j$ in month $t$, and $\mathrm{AE}_{\mathrm{ct}}$ is the advertising expenditure for commercial $\mathrm{c}$ and month $\mathrm{t}$.

Note that Informational ${ }_{\mathrm{jt}}$ and Emotional ${ }_{\mathrm{jt}}$ do not necessarily correlate with advertising spending: these variables depend only on the content of the ads in that month and the proportion of the monthly spending allocated to each ad and not on the level of spending in a specific month. In addition, note that the advertising content variables are undefined for months where the total spending for coded ads is zero. To avoid having missing data, we coded undefined values as zero and created a dummy variable (NoContent $\mathrm{j}_{\mathrm{j}}$ ) indicating when this was the case. We included the dummy in the models to capture differences in the levels of online search and sales for periods when

\footnotetext{
${ }^{3}$ Prior studies (Chandy et al. 2001; Liaukonyte, Teixeira, and Wilbur 2015) have also operationalized the informational and emotional ad content variables as the sum of the number of informational and emotional cues in an ad.
} 


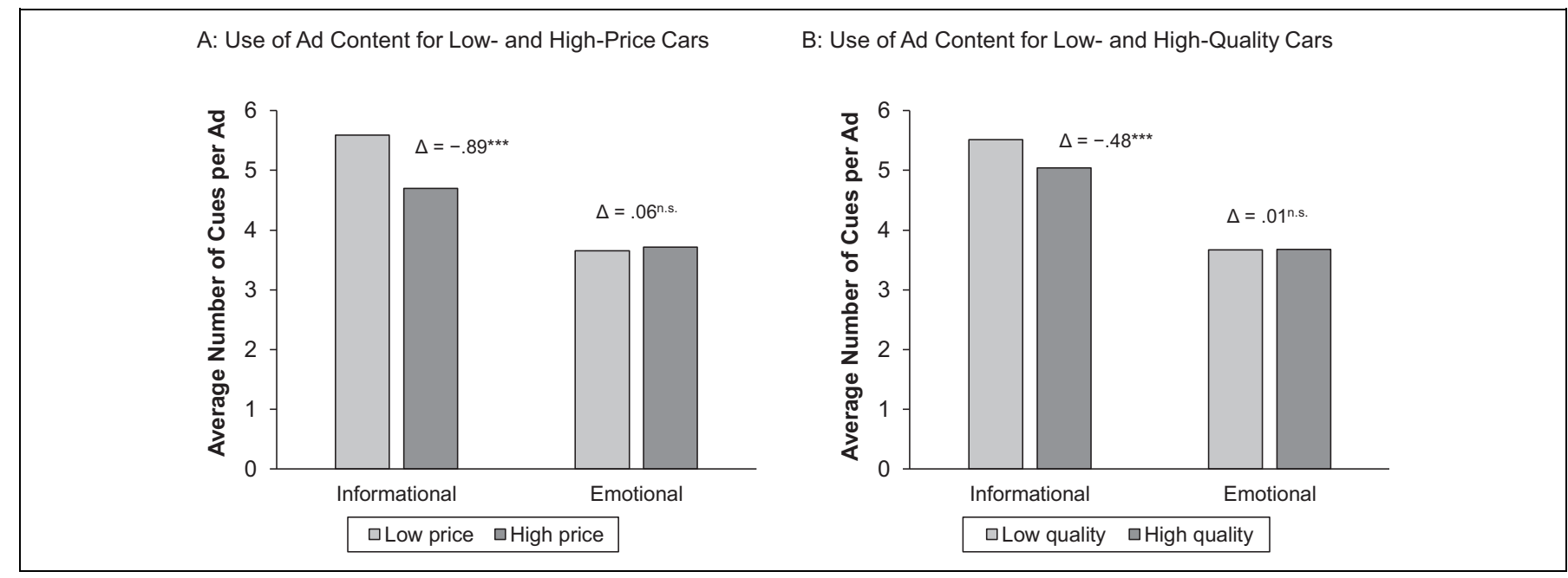

Figure 2. Ads for high-price and high-quality products contain fewer informational cues than ads for low-price and low-quality products, although they do not differ in the number of emotional cues.

n.s. Not significant.

$* * * p<.01$.

we had and did not have ad content data. We also added the interaction between the dummy and advertising stock to capture potential differences in advertising elasticity.

\section{Car Positioning: Price and Quality}

We obtained annual data about manufacturer suggested retail prices from Ward's Auto. Following prior research, we use manufacturer-suggested retail prices instead of transaction prices, which are not available to us (Balachander, Liu, and Stock 2009). We calculated the average between 2007 and 2010 to create the variable Price ${ }_{j}$. To operationalize product quality, we obtained aggregated online quality ratings from J.D. Power's Initial Quality Study, J.D. Power's Vehicle Dependability Study, and U.S. News' Reliability Study for 2008 car models. ${ }^{4}$ A factor analysis on the three individual ratings indicates that all of them load on one dimension. Therefore, we operationalized quality (Qual$\left.i_{\mathrm{j}}\right)$ as the average of these different ratings. The correlation between Price ${ }_{j}$ and Quality ${ }_{\mathrm{j}}$ is positive but small $(\mathrm{r}=.11, p$ $=.19$ ). In the sample, there are cheap cars with high quality scores (e.g., Chevrolet Malibu, Toyota RAV4) and expensive cars with low quality scores (e.g., Audi A5, Infinity QX56).

Panels A and B in Figure 2 reveal the levels of informational and emotional content in ads for cars for which the price and quality are below and above the mean (low and high conditions, respectively). An analysis of variance indicates that highprice cars use less informational $(\Delta=-.89, p<.01)$ and the

\footnotetext{
${ }^{4}$ We used earlier ratings when the 2008 rating was not available and the earliest available rating for cars introduced after that year. Robustness checks indicate that our results are stable when we use 2007 quality ratings (and price) or time-varying quality ratings (and price).
}

same emotional $(\Delta=.06, p>.1)$ ad content than low-price cars do. The amount of informational content is also lower for high-quality cars $(\Delta=-.48, p<.01)$, and these cars do not seem to use more emotional content in their ads than lowquality cars do $(\Delta=.01, p>.1)$.

\section{Other Variables Driving Sales and Online Search}

We also collected several control variables that may drive online search and sales. First, we considered the MSRP of the car $\left(\right.$ Price $\left._{\mathrm{jt}}\right)$; this variable exhibits longitudinal variation only at the yearly level. Second, we included competitive advertising stock (CompAdStock $\mathrm{j}_{\mathrm{j} t}$ ), calculated using the formula in Equation 2, a carryover parameter specific to this stock variable, and the sum of the advertising expenditures of competitors in the same competitive group. We defined the competitive group as cars with the same body type (SUV or sedan) produced by competing brands in the same segment (premium or nonpremium, as defined by the registration data provider). Third, we integrated the University of Michigan's consumer sentiment index $\left(\right.$ ConsumSentIndex ${ }_{\mathrm{jt}}$ ), a well-established indicator of the state of the economy and consumer willingness to spend. Fourth, we include dummy variables to indicate the first six months after a model introduction and months in years in which a car model was not manufactured (Intro $\mathrm{j}_{\mathrm{jt}}$ and Exit $_{\mathrm{jt}}$, respectively).

To control for environmental and seasonal effects, we included the total unit sales in the competitive group (CompSales $_{\mathrm{jt}}$ ), and the total number of online searches in the "Autos \& Vehicles" category (TotalOnlineSearch ${ }_{t}$ ) from Google Trends. We also considered the monthly national average gas prices $\left(\right.$ GasPrice $\left._{t}\right)$, obtained from the Energy Information Administration website. Finally, we included the fuel efficiency of a car, in miles per dollar $\left(\right.$ MPDollar $\left._{\mathrm{jt}}\right)$, calculated 
as the combined miles per gallon ${ }^{5}$ of a car divided by the gas price (in dollars per gallon).

The final data set for this study includes information about 144 car models from 20 brands in the sedan and SUV segments, spanning January 2007 to September 2010. The total revenue considered in the sample is $\$ 566.3$ billion. The average number of units sold per month and car model is 3,860 at an average price of $\$ 33,536$. The average monthly revenue is $\$ 96.56$ million per car model, whereas the average monthly television advertising spending is $\$ 2.12$ million per model. On average, television ad spending represents around $2.2 \%$ of revenues. To our knowledge, our data contain the largest television advertising coding effort to date, doubling the number of coded ads used by Liaukonyte, Teixeira, and Wilbur (2015) and covering 144 products, again doubling the number of products considered in prior studies on ad content (e.g., Becker, Wiegand, and Reinartz 2019).

\section{Methodology}

In this section, we specify a model for online search and sales. We assume that ad content affects sales through its impact on advertising elasticity, in line with the conceptual framework in Figure 1. To model this impact, we add the two-way interaction between advertising stock and ad content (informational and emotional). We also include the three-way interaction among these variables and car characteristics (i.e., price and quality) to determine how the impact of ad content on advertising elasticity depends on the product's positioning. Adding the two- and three-way interactions to the search and sales equations enables us to express advertising elasticity as a function of ad content and car characteristics, as we subsequently demonstrate.

\section{Model Specification}

Similar to extant research, we specify a model that accounts for the dynamic effects of advertising using panel data (Burmester et al. 2015; Dinner, Van Heerde, and Neslin 2014; Luan and Sudhir 2010). We use the logarithm of the volume of online search and sales as our dependent variables. This specification accounts for nonlinearities and allows us to obtain the advertising elasticity directly, which facilitates comparability with other studies. We include the advertising stock ( AdStock $_{\mathrm{jt}}$ ) variable (that accounts for the dynamic effects of advertising), interaction effects, and the control variables mentioned previously. Formally, we specify the volume of online search for car model $\mathrm{j}$ in month $\mathrm{t}$ as

\footnotetext{
${ }^{5}$ To calculate combined miles per gallon, we used the formula proposed by the Environmental Protection Agency: 1/(.45/cityMPG+.55/hwyMPG), where cityMPG and hwyMPG are the miles per gallon in city and highway respectively. We obtained the cityMPG and hwyMPG variables from Ward's Auto.
}

$$
\begin{aligned}
& \ln \left(\text { OnlineSearch }_{\mathrm{jt}}\right) \\
& =\alpha_{\mathrm{j}}^{\mathrm{OS}}+\beta_{1}^{\text {OS }} \text { AdStock }_{\mathrm{jt}}+\beta_{2}^{\text {OS }} \text { AdStock }_{\mathrm{jt}} \times \text { Informational }_{\mathrm{jt}} \\
& +\beta_{3}^{\text {OS }} \text { AdStock }_{\mathrm{jt}} \times \text { Informational }_{\mathrm{jt}} \times \ln \left(\text { Price }_{\mathrm{j}}\right) \\
& +\beta_{4}^{\text {OS }} \text { AdStock }_{\mathrm{jt}} \times \text { Informational }_{\mathrm{jt}} \times \text { Quality }_{\mathrm{j}} \\
& +\beta_{5}^{\text {OS }} \text { AdStock }_{\mathrm{jt}} \times \text { Emotional }_{\mathrm{jt}}+\beta_{6}^{\text {OS }} \text { AdStock }_{\mathrm{jt}} \\
& \times \text { Emotional }_{\mathrm{jt}} \times \ln \left(\text { Price }_{\mathrm{j}}\right)+\beta_{7}^{\text {OS }} \text { AdStock }_{\mathrm{jt}} \\
& \times \text { Emotional }_{\mathrm{jt}} \times \text { Quality }_{\mathrm{j}}+\delta_{1}^{\text {OS }} \ln \left(\text { Price }_{\mathrm{jt}}\right) \\
& +\delta_{2}^{\text {OS }} \text { CompAdStock }_{\text {jt }}+\delta_{3}^{\text {OS }} \ln \left(\text { ConsumSentIndex }_{\mathrm{t}}\right) \\
& +\delta_{4}^{\mathrm{OS}} \text { Intro }_{\mathrm{jt}}+\delta_{5}^{\mathrm{OS}} \text { Exit }_{\mathrm{jt}}+\delta_{6}^{\mathrm{OS}} \ln \left(\text { TotalOnlineSearch }_{\mathrm{t}}\right) \\
& +\delta_{7}^{\mathrm{OS}} \ln \left(\text { GasPrice }_{\mathrm{t}}\right)+\sum \alpha_{\mathrm{t}}^{\mathrm{OS}}+\sum \gamma_{\mathrm{i}}^{\mathrm{OS}} \mathrm{LOE}_{\mathrm{i}}+\epsilon_{\mathrm{jt}}^{\mathrm{OS}} \text {, }
\end{aligned}
$$

where $\alpha_{j}^{\text {OS }}$ are product-specific fixed effects that capture heterogeneity at the car model level, and $\sum \alpha_{t}^{\text {OS }}$ represents 12month fixed effects to capture seasonal effects that are common across products. The term $\mathrm{LOE}_{\mathrm{i}}$ represents all lower-order effects involving the variables that moderate advertising effectiveness, which we must control for to make correct statistical inferences about the three-way interaction coefficients (Ghosh, Dutta, and Stremersch 2006). Note that the price and quality variables included in the interactions ( Price $_{j}$ and Quality $_{j}$ ) do not vary over time. This feature of the model enables us to interpret the coefficients of the interactions as heterogeneity across cars due to their differences in positioning (as opposed to changes in positioning within cars). Also note that there is no main effect of Price ${ }_{j}$ and Quality $y_{j}$ in the model because these are perfectly collinear with the fixed effects. For interpretability, we standardize all the moderating variables in Equation 3 (and Equation 5).

Given Equation 3, the online search elasticity to advertising ${ }^{6}$ is

$$
\begin{aligned}
& \eta_{\mathrm{jt}}^{\mathrm{OS}}=\frac{\mathrm{d} \ln \left(\text { OnlineSearch }_{\mathrm{jt}}\right)}{\mathrm{d} \text { AdStock }_{\mathrm{jt}}} \\
& =\beta_{1}^{\text {OS }}+\beta_{2}^{\text {OS }} \text { Informational }_{\mathrm{jt}}+\beta_{3}^{\text {OS }} \text { Informational }_{\mathrm{jt}} \\
& \times \ln \left(\text { Price }_{\mathrm{j}}\right)+\beta_{4}^{\text {OS }} \text { Informational }_{\mathrm{jt}} \times \text { Quality }_{\mathrm{j}} \\
& +\beta_{5}^{\text {OS }} \text { Emotional }_{\mathrm{jt}}+\beta_{6}^{\mathrm{OS}} \text { Emotional }_{\mathrm{jt}} \times \ln \left(\text { Price }_{\mathrm{j}}\right) \\
& +\beta_{7}^{\text {OS }} \text { Emotional }_{\mathrm{jt}} \times \text { Quality }_{\mathrm{j}}+\gamma_{1}^{\text {OS }} \ln \left(\text { Price }_{\mathrm{j}}\right) \\
& +\gamma_{2}^{\text {OS }} \text { Quality }_{\mathrm{j}} \text {. }
\end{aligned}
$$

According to this expression, the coefficients of the two-way interactions in Equation 3 enable us to directly test how ad content affects advertising elasticity at the online search stage. For instance, we can formally test the impact of informational

\footnotetext{
${ }^{6}$ Given the specification of the advertising stock in Equation 2, the elasticities in Equations 4 and 6 represent long-term elasticities (Danaher, Bonfrer, and Dhar 2008; Dinner, Van Heerde, and Neslin 2014).
} 
content by checking the sign and significance of $\beta_{2}^{\mathrm{OS}}$, and we can test the moderating effect of price on the previous impact by checking the sign and significance of $\beta_{3}^{\text {OS }}$. Because the moderating variables are standardized, the coefficients denote the effect of a change in one standard deviation in a focal variable at the average level of the others. For instance, $\beta_{2}^{\text {OS }}$ represents the impact on advertising elasticity of an increase in one standard deviation in informational content (at an average level of emotional content, price, and quality), and $\beta_{3}^{\text {OS }}$ represents the change in the previous impact with an increase in one standard deviation in price (at an average level of emotional content and quality).

In the sales equation, we include the online search stock (OnlineSearchStock ${ }_{\mathrm{jt}}$ ) to account for the dynamic effects of online search. We also add the two-way interactions between online search stock and car characteristics to assess how the impact of online search on sales varies across products. Formally, we model the sales for car model $j$ in month $t$ as

$$
\begin{aligned}
\ln \left(\text { Sales }_{\mathrm{jt}}\right)= & \alpha_{\mathrm{j}}^{\mathrm{S}}+\beta_{10}^{\mathrm{S}} \text { AdStock }_{\mathrm{jt}}+\beta_{11}^{\mathrm{S}} \text { AdStock }_{\mathrm{jt}} \\
& \times \text { Informational }_{\mathrm{jt}}+\beta_{12}^{\mathrm{S}} \text { AdStock }_{\mathrm{jt}} \\
& \times \text { Informational }_{\mathrm{jt}} \times \ln \left(\text { Price }_{\mathrm{j}}\right) \\
& +\beta_{13}^{\mathrm{S}} \text { AdStock }_{\mathrm{jt}} \times \text { Informational }_{\mathrm{jt}} \times \text { Quality }_{\mathrm{j}} \\
& +\beta_{14}^{\mathrm{S}} \text { AdStock }_{\mathrm{jt}} \times \text { Emotional }_{\mathrm{jt}} \\
& +\beta_{15}^{\mathrm{S}} \text { AdStock }_{\mathrm{jt}} \times \text { Emotional }_{\mathrm{jt}} \times \ln \left(\text { Price }_{\mathrm{j}}\right) \\
& +\beta_{16}^{\mathrm{S}} \text { AdStock }_{\mathrm{jt}} \times \text { Emotional }_{\mathrm{jt}} \times \text { Quality }_{\mathrm{j}} \\
& +\beta_{20}^{\mathrm{S}} \text { OnlineSearchStock }_{\mathrm{jt}} \\
& +\beta_{21}^{\mathrm{S}} \text { OnlineSearchStock }_{\mathrm{jt}} \times \ln \left(\text { Price }_{\mathrm{j}}\right) \\
& +\beta_{22}^{\mathrm{S}} \text { OnlineSearchStock }_{\mathrm{jt}} \times \text { Quality }_{\mathrm{j}} \\
& +\delta_{1}^{\mathrm{S}} \ln \left(\text { Price }_{\mathrm{jt}}\right)+\delta_{2}^{\mathrm{S}} \text { CompAdStock }_{\mathrm{jt}} \\
& +\delta_{3}^{\mathrm{S}} \operatorname{Intro}_{\mathrm{jt}}+\delta_{4}^{\mathrm{S}} \text { Exit }_{\mathrm{jt}} \\
& +\delta_{5}^{\mathrm{S}} \ln \left(\text { ConsumSentIndex }_{\mathrm{t}}\right) \\
& +\delta_{6}^{\mathrm{S}} \ln \left(\text { CompSales }_{\mathrm{t}}\right)+\delta_{7}^{\mathrm{S}} \ln \left(\text { MPDollar }_{\mathrm{jt}}\right) \\
& +\sum{ }_{\mathrm{t}}^{\mathrm{S}}+\sum \gamma_{\mathrm{i}}^{\mathrm{S}} \text { LOE }_{\mathrm{i}}+\varepsilon_{\mathrm{jt}}^{\mathrm{S}},
\end{aligned}
$$

where $\alpha_{j}^{S}$ are car-specific fixed effects that control for differences in the level of sales across products, $\sum \alpha_{t}^{S}$ represents the 12-month fixed effects, and $\mathrm{LOE}_{\mathrm{i}}$ refers to the lower-order effects.

The two- and three-way interactions in Equation 5 enable us to directly test the effects of ad content on the sales elasticity to advertising. For instance, we can look at the sign and significance of $\beta_{11}^{\mathrm{S}}$ to formally test the impact of informational content, and we can check the sign and significance of $\beta_{12}^{S}$ to test the moderating effect of price on the previous impact.

Considering Equations 3 and 5 together, we can calculate the total sales elasticity to advertising $\left(\eta^{S}\right)$ as a function of ad content and car characteristics (for the proof, see Web Appendix C):

$$
\begin{aligned}
\eta_{\mathrm{jt}}^{\mathrm{S}}= & \frac{\mathrm{d} \ln \left(\text { Sales }_{\mathrm{jt}}\right)}{\mathrm{d} \mathrm{AdStock}_{\mathrm{jt}}} \\
= & \frac{\partial \ln \left(\text { Sales }_{\mathrm{jt}}\right)}{\partial \text { AdStock }_{\mathrm{jt}}}+\frac{\partial \ln \left(\text { Sales }_{\mathrm{jt}}\right)}{\partial \ln \left(\text { Online Search }_{\mathrm{jt}}\right)} \\
& \times \frac{\mathrm{d} \ln \left(\text { Online Search }_{\mathrm{jt}}\right)}{\mathrm{d} \text { AdStock }_{\mathrm{jt}}} .
\end{aligned}
$$

In this equation, the advertising elasticity of sales is the sum of two different components (first and second terms in the righthand side of the equation): the direct effect $\left(\mathrm{DE}_{\mathrm{jt}}\right)$ of advertising on sales and the indirect effect $\left(\mathrm{IE}_{\mathrm{jt}}\right)$ of advertising on sales through online search. Expanding Equation 6, we have

$$
\begin{aligned}
& \mathrm{DE}_{\mathrm{jt}}=\beta_{10}^{\mathrm{S}}+\beta_{11}^{\mathrm{S}} \text { Informational }_{\mathrm{jt}}+\beta_{12}^{\mathrm{S}} \text { Informational }_{\mathrm{jt}} \\
& \times \ln \left(\text { Price }_{\mathrm{j}}\right)+\beta_{13}^{\mathrm{S}} \text { Informational }_{\mathrm{jt}} \times \text { Quality }_{\mathrm{j}} \\
& +\beta_{14}^{\mathrm{S}} \text { Emotional }_{\mathrm{jt}}+\beta_{15}^{\mathrm{S}} \text { Emotional }_{\mathrm{jt}} \times \ln \left(\text { Price }_{\mathrm{j}}\right) \\
& +\beta_{16}^{\mathrm{S}} \text { Emotional }_{\mathrm{jt}} \times \text { Quality }_{\mathrm{j}}+\gamma_{1}^{\mathrm{S}} \ln \left(\text { Price }_{\mathrm{j}}\right) \\
& +\gamma_{2}^{\mathrm{S}} \text { Quality }_{\mathrm{j}} \text {, } \\
& \mathrm{IE}_{\mathrm{jt}}=\left(\beta_{20}^{\mathrm{S}}+\beta_{21}^{\mathrm{S}} \ln (\text { Price })+\beta_{22}^{\mathrm{S}} \text { Quality }\right) \\
& \left(\beta_{1}^{\text {OS }}+\beta_{2}^{\text {OS }} \text { Informational }_{\mathrm{jt}}+\beta_{3}^{\text {OS }} \text { Informational }_{\mathrm{jt}}\right. \\
& \times \ln \left(\text { Price }_{\mathrm{j}}\right)+\beta_{4}^{\text {OS }} \text { Informational }_{\mathrm{jt}} \times \text { Quality }_{\mathrm{j}} \\
& +\beta_{5}^{\text {OS }} \text { Emotional }_{\mathrm{jt}}+\beta_{6}^{\text {OS }} \text { Emotional }_{\mathrm{jt}} \times \ln \left(\text { Price }_{\mathrm{j}}\right) \\
& +\beta_{7}^{\text {OS }} \text { Emotional }_{\mathrm{jt}} \times \text { Quality }_{\mathrm{j}}+\gamma_{1}^{\mathrm{OS}} \ln \left(\text { Price }_{\mathrm{j}}\right) \\
& +\gamma_{2}^{\text {OS }} \text { Quality }_{\mathrm{j}} \text { ). }
\end{aligned}
$$

We use Equations 6-8 to examine how the effect of ad content on the total sales elasticity to advertising varies according to the positioning of cars.

\section{Endogeneity}

Our model accounts for the potential endogeneity of price, advertising spending, and ad content in the search equation (Equation 3) and of price, advertising spending, ad content, and online search in the sales equation (Equation 5). Endogeneity may arise for several reasons. First, car characteristics that remain constant over time (e.g., design, aerodynamics) would influence online search and sales and also determine the price, advertising spending, and ad content. Not including these characteristics in the model would lead to biased parameters for the marketing variables. Including car-specific fixed effects helps control for this omitted variable problem (Burmester et al. 2015; Papies, Ebbes, and Van Heerde 2017).

Second, exogenous shocks might systematically affect the dependent and marketing variables over time. For example, automakers generally perform end-of-year sales promotions to get rid of excess inventory, offering financial incentives that we do not observe. By including month-specific fixed effects, we can control for shocks that change over time but are 
common across manufacturers (Papies, Ebbes, and Van Heerde 2017).

Third, there could be unobserved variables (e.g., price cuts, advertising in media other than television) that change over time at the car level and simultaneously drive sales and managerial decisions regarding ad content, television advertising spending, and price. In addition, there could be unobserved factors that simultaneously drive online search and sales (e.g., product reviews). We address this omitted variable problem with a Gaussian copulas approach (Park and Gupta 2012). Gaussian copulas model the correlation between the error term and the endogenous variables. When they are included in regressions, they control for the parts of the endogenous variables that correlate with the error term. The Gaussian copula approach does not require instrumental variables, which often are difficult to find. The copula for an endogenous variable $X_{\mathrm{jt}}$ is calculated as Copula $\left(\mathrm{X}_{\mathrm{jt}}\right)=\Phi^{-1}\left[\mathrm{H}_{\mathrm{X}}\left(\mathrm{X}_{\mathrm{jt}}\right)\right]$, where $\Phi^{-1}$ is the inverse of the cumulative distribution function of the standard normal distribution, and $\mathrm{H}_{\mathrm{X}}$ is the empirical distribution function of the focal endogenous variable $\mathrm{X}_{\mathrm{jt}}$. Identification in the copula approach requires that the endogenous variables are not normally distributed. Visual inspection of the histograms and results from Shapiro-Wilk tests confirm that the endogenous variables are not normally distributed (OnlineSearchStock: $\mathrm{W}=.729, p<.01 ;$ AdStock: $\mathrm{W}=.969, p<.01 ; \ln$ (Price): $\mathrm{W}=.989, p<.01$; Informational: $\mathrm{W}=.993, p<.01$; Emotional: $\mathrm{W}=.994, p<.01)$.

Fourth, managers could use their private information about how consumers respond to marketing actions to set the level of advertising spending, ad content, and price. For example, they might decide to spend more on cars with higher advertising elasticity or in campaigns with more effective ad content (either informational or emotional). If this choice is unaccounted for, the estimation could suffer from slope endogeneity (Luan and Sudhir 2010). Therefore, in the regressions we include the interaction between the copulas and their respective endogenous variables (Park and Gupta 2012).

We estimate Equations 3 and 5 separately using ordinary least squares. ${ }^{7}$ We report bootstrap standard errors with 5,000 repetitions as suggested by Park and Gupta (2012). Finally, to estimate the carryover parameters $(\lambda)$, we perform a grid search from 0 to 1 in steps of .05 over the sum of squared residuals of the online search and sales equations.

\section{Results}

The results from the search and sales equations show good fit $\left(\mathrm{R}^{2}\right.$ of $75.4 \%$ and $90.2 \%$ for the search and sales equations, respectively). The variance inflation factor values of the focal variables (i.e., AdStock, OnlineSearchStock, and their interactions) are all 7.5 or less, and thus multicollinearity is not a

\footnotetext{
${ }^{7}$ The correlation between the residuals in Equations 3 and 5 is nonsignificant ( $\mathrm{r}$ $=-.001, p=.96$ ), which indicates that simultaneous estimation is not necessary in our application. As a robustness check, we also estimated the equations simultaneously, and the results hold.
}

concern. To assess the value of including ad content and online search in the models, we estimated Equations 3 and 5 without these variables. We report these analyses in Tables 3 and 4 for online search and sales, respectively. In terms of model performance, the log-likelihood and Akaike information criterion suggest that the full models outperform those without ad content or without online search stock. ${ }^{8}$ Thus, incorporating ad content and online search stock increases the explanatory power of the models. Given their superiority, we focus on the results of the full models in the following discussion.

\section{Advertising Elasticity in the Online Search Equation}

The advertising stock coefficient is positive and marginally significant in the online search equation, suggesting that television advertising has a positive impact on the volume of online searches $\left(\beta_{1}^{\mathrm{OS}}=.032, p<.1\right)$. This coefficient represents the long-term elasticity of advertising campaigns with average levels of informational and emotional content for a car with an average price and quality level (all moderators are standardized).

The coefficient for the interaction between advertising stock and informational content is negative but nonsignificant $\left(\beta_{2}^{\mathrm{OS}}=-.003, p>.1\right)$. Thus, the amount of informational content in ads does not seem to influence the effectiveness of advertising for generating online search. This conclusion seems valid for all cars, regardless of their price and quality levels, because the coefficients of the three-way interactions are not significant (interaction with price: $\beta_{3}^{\mathrm{OS}}=.006, p>.1$; interaction with quality: $\beta_{4}^{\mathrm{OS}}=-.006, p>.1$ ).

The coefficient for the interaction between advertising stock and emotional content is positive and significant $\left(\beta_{5}^{\mathrm{OS}}=.016\right.$, $p<.05$ ). Therefore, an increase in emotional content has a positive impact on advertising elasticity. This is in line with the idea that emotional content can generate positive feelings that increase interest for the product and, thus, online search. The coefficients for the three-way interactions with price and quality are not significant $\left(\beta_{6}^{\text {OS }}=-.002, p>.1 ; \beta_{7}^{\text {OS }}=.002\right.$, $p>.1$ ), so the positive impact of emotional content does not seem to depend on the positioning of products.

\section{Advertising Elasticity in the Sales Equation}

We find a positive and significant direct impact of advertising on sales $\left(\beta_{10}^{\mathrm{S}}=.188, p<.01\right)$. This coefficient is close to the mean long-term value of advertising elasticity of .24 reported in a meta-analysis by Sethuraman, Tellis, and Briesch (2011).

We find that the coefficient for the interaction between advertising stock and informational content is positive and significant $\left(\beta_{11}^{\mathrm{S}}=.032, p<.01\right)$. Thus, for an average car, informational content increases advertising elasticity in line with the

\footnotetext{
${ }^{8}$ These results are also supported by F-tests. Sales equation: Full versus no ad content, $\mathrm{F}=29.45, p<.01$; full vs no online search, $\mathrm{F}=55.42, p<.01$. Online search equation: Full versus no ad content, $\mathrm{F}=2.07, p<.01$.
} 
Table 3. Parameter Estimates for the Online Search Equation.

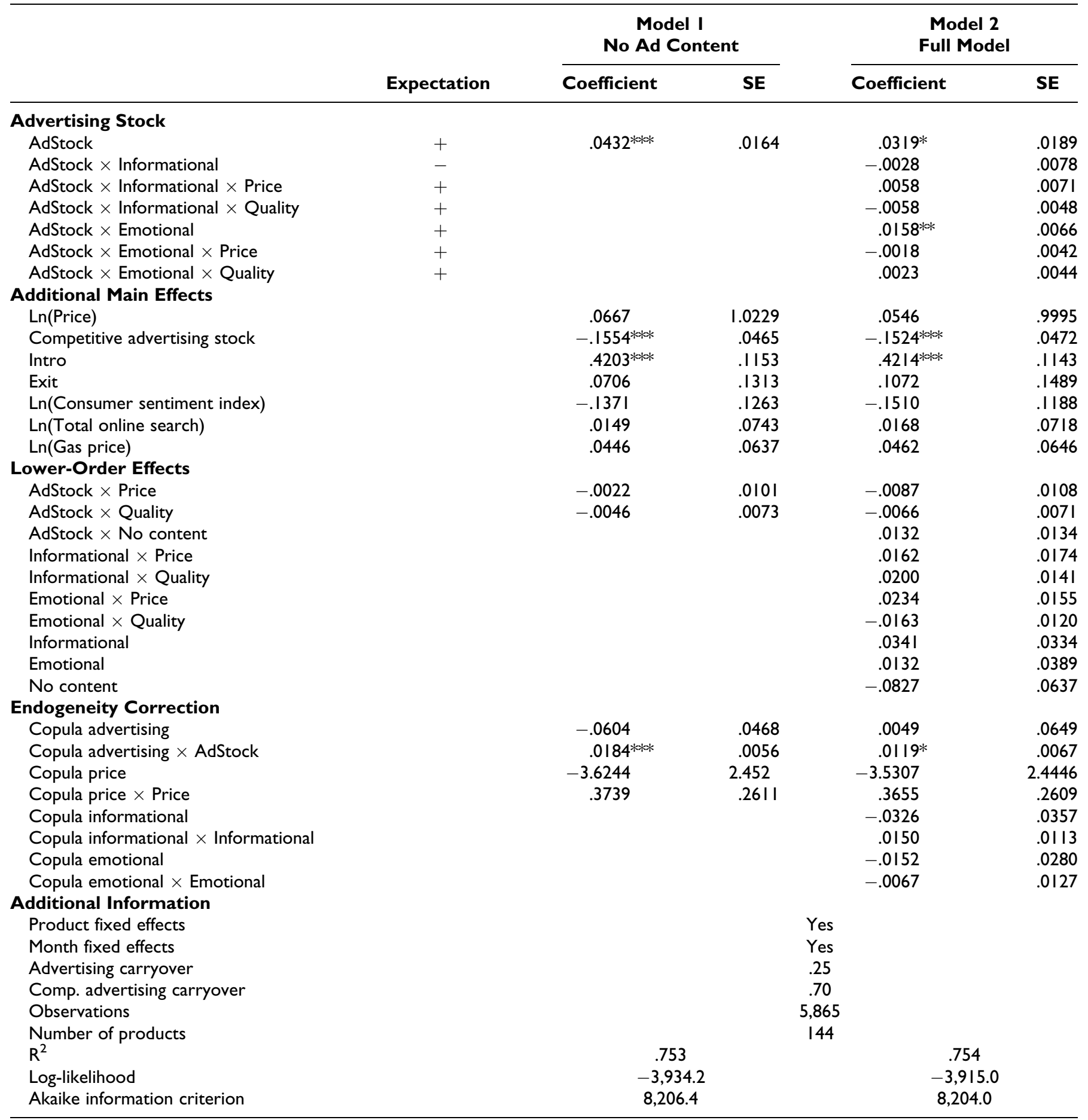

$*_{p}<.1$.

$* * p<.05$.

$* * * p<.01$.

Notes: Two-tailed tests of significance.

idea that additional information in ads reduces uncertainty. Moreover, the coefficient of the three-way interaction with price is negative and significant $\left(\beta_{12}^{\mathrm{S}}=-.022, p<.05\right)$, suggesting that the impact of an increase in informational content on advertising elasticity is smaller for high-price cars than for low-price cars. We also find that the effect of an increase in informational content on advertising elasticity is smaller for high-quality cars than for low-quality cars $\left(\beta_{13}^{\mathrm{S}}=-.017\right.$, 
Table 4. Parameter Estimates for the Sales Equation.

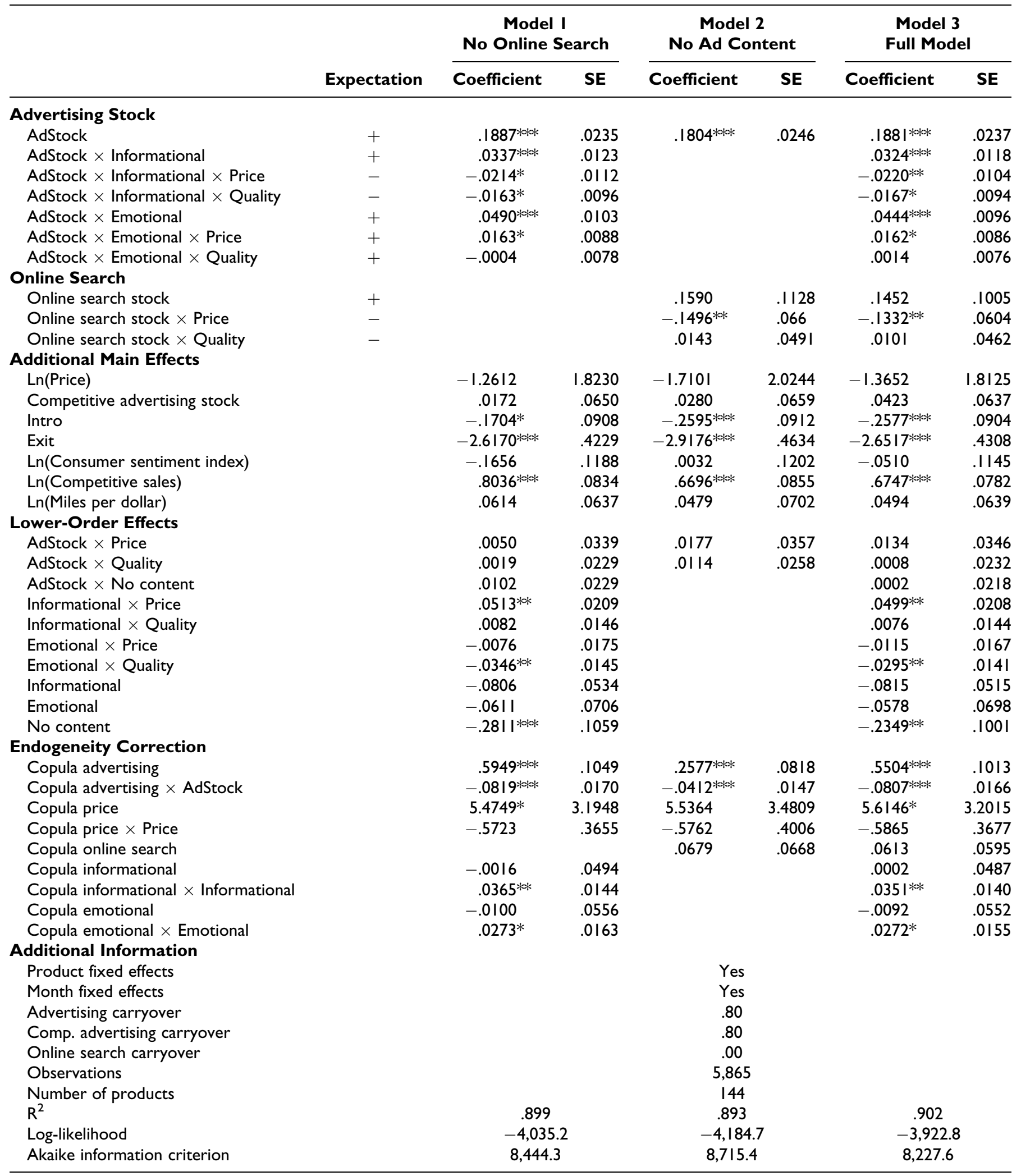

$* p<. I$.

$* * p<.05$.

$* * * p<.01$.

Notes: Two-tailed tests of significance. 
Table 5. Indirect and Total Advertising Effects on Sales at Different Product Prices.

\begin{tabular}{lccc}
\hline Product Price & Indirect Effect (Through Online Search) & Total Effect & Indirect Effect as Percentage of Total Effect \\
\hline$\$ 12,836$ & $.020^{*}$ & $.208^{* * *}$ & $9.42 \%$ \\
$\$ 15,245$ & $.017^{*}$ & $.205^{* * *}$ & $8.16 \%$ \\
$\$ 18,106$ & $.014^{*}$ & $.202^{* * *}$ & $6.91 \%$ \\
$\$ 21,504$ & $.011^{*}$ & $.199 * * *$ & $5.67 \%$ \\
$\$ 25,540$ & $.009 *$ & $.197^{* * *}$ & $4.44 \%$ \\
$\$ 30,333$ & .006 & $.194^{* * *}$ & $3.23 \%$ \\
$\$ 36,026$ & .004 & $.192^{* * *}$ & $2.03 \%$ \\
$\$ 42,787$ & .002 & $.190^{* * *}$ & $.84 \%$ \\
$\$ 50,818$ & -.001 & $.188^{* * *}$ & $-.32 \%$ \\
$\$ 60,355$ & -.003 & $.185^{* * *}$ & $-1.46 \%$ \\
$\$ 71,682$ & -.005 & $.183^{* * *}$ & $-2.57 \%$
\end{tabular}

$*_{p}<. \mathrm{l}$.

$* * p<.05$.

$* * * p<.01$.

Notes: Two-tailed tests of significance. The direct effect of advertising on sales is equal to .188 and it does not change with price

$p<.1)$. These findings are in line with the theoretical argument that the uncertainty reduction effects of informational content are larger for low-price and low-quality cars than for high-price and high-quality cars.

The coefficient for the interaction between advertising stock and emotional content is positive and significant $\left(\beta_{14}^{\mathrm{S}}=.044, p\right.$ $<.01$ ), implying that an increase in emotional content leads to higher advertising elasticities. This finding is in line with the idea that emotional content helps persuading consumers. Furthermore, the effect is higher for high-price cars than for low-price cars $\left(\beta_{15}^{\mathrm{S}}=.016, p<.1\right)$, in line with the idea that emotions are more persuasive when consumers evaluate valueexpressive products. The effect of emotional content does not change with car quality $\left(\beta_{16}^{\mathrm{S}}=.001, p>.1\right)$.

\section{Impact of Online Search on Sales}

The coefficient of online search stock in the sales equation is nonsignificant $\left(\beta_{20}^{\mathrm{S}}=.145, p>.1\right)$. However, the effect significantly increases as the prices of cars decrease $\left(\beta_{21}^{\mathrm{S}}=\right.$ $-.133, p<.05)$. To assess how the impact of online search on sales varies with price, we use a floodlight analysis (Spiller et al. 2013). We calculate the confidence intervals using simulation methods based on the estimated coefficients, their variance-covariance matrix, and 50,000 draws (Krinsky and Robb 1986). We find that a $10 \%$ increase in the volume of online search leads to a $3.6 \%$ increase in sales for a $\$ 15,000$ car. However, the same increase in online search leads to a $.6 \%$ decrease in sales for a $\$ 60,000$ car. The effect of online search on sales is positive for cars priced below $\$ 26,000$, but it is nonsignificant for cars above this price (we provide details in Web Appendix D). These results are in line with the ideas that uncertainty reduction is more important for low-price cars and that the proportion of transactional versus recreational searches is higher for low-price cars than for high-price cars. The relationship between online search and sales does not seem to depend on the quality of the $\operatorname{car}\left(\beta_{22}^{\mathrm{S}}=.010, p>.1\right)$.

\section{Indirect and Total Effects of Advertising on Sales}

Advertising influences sales directly and indirectly through online search. To calculate the indirect effect of advertising on the sales of cars with different prices, we use Equation 8. ${ }^{9}$ We calculate the standard errors required to test for statistical significance using the aforementioned simulation methods. We show the results in Table 5. For a $\$ 15,000$ car, the indirect effect is positive and represents approximately $8 \%$ of the total advertising effect. However, for a $\$ 60,000$ vehicle, the indirect effect is nonsignificant. This finding suggests that for low-price cars, an important part of the advertising's capacity to generate sales comes from its capacity to generate online search (i.e., indirect effect), whereas, for expensive cars, stimulating consumers to search online does not seem to affect ad effectiveness.

In addition, in the sales model without online search (Model 1 in Table 4), the total advertising elasticity is constant regardless of the price of the car (the coefficient for the interaction between advertising stock and the logarithm of price is nonsignificant). However, the full model indicates that total advertising elasticity depends on the product's price (because the indirect effect depends on price). Thus, the sales model that omits online search yields a biased advertising elasticity because it fails to capture the heterogeneity in the indirect effect of advertising.

We calculate the total impact of ad content on the sales elasticity to advertising for cars with different prices and quality ratings (from Equations 7 and 8) using a floodlight analysis. We present the marginal effect of an increase of one standard deviation of content on the sales elasticity to advertising in Figure 3 (we report the formulas in Web Appendix E). Panel A shows that the effect of informational content decreases as

\footnotetext{
${ }^{9}$ Assuming that the informational and emotional variables are at their mean levels, the indirect effect is given by $\mathrm{IE}=\left[\beta_{20}^{\mathrm{S}}+\beta_{21}^{\mathrm{S}} \ln (\right.$ Price $)+$ $\beta_{22}^{\mathrm{S}}$ Quality $]\left[\beta_{1}^{\text {OS }}+\gamma_{1}^{\text {OS }} \ln \left(\right.\right.$ Price $\left._{\mathrm{j}}\right)+\gamma_{2}^{\text {OS }}$ Quality $\left._{\mathrm{j}}\right]$.
} 
A: Change in Total Advertising Elasticity Due to an Additional SD in Informational Content at Different Prices

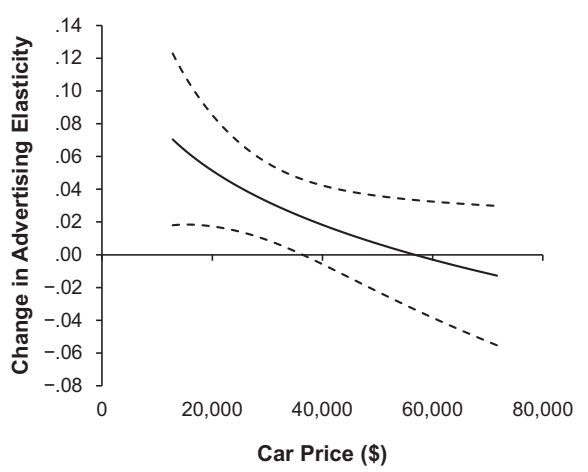

C: Change in Total Advertising Elasticity Due to an Additional SD in Informational Content at Different Quality Ratings

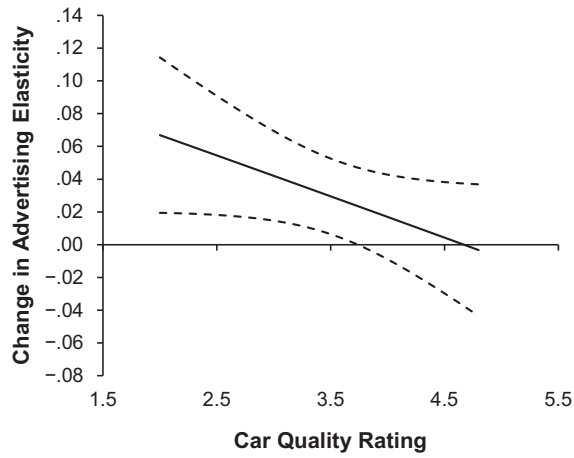

B: Change in Total Advertising Elasticity Due to an

Additional SD in Emotional Content at Different Prices

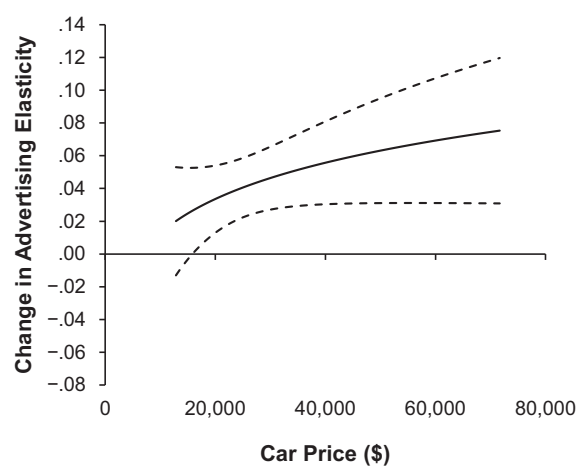

D: Change in Total Advertising Elasticity Due to an Additional SD in Emotional Content at Different Quality Ratings

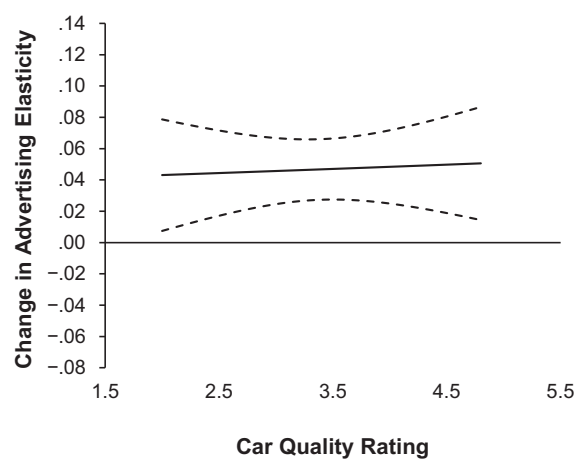

Figure 3. For high-price and high-quality (low-price and low-quality) products, an increase in emotional (informational) content generates more sales than an increase in informational (emotional) content.

Notes: Dotted lines represent $95 \%$ confidence intervals.

the price of cars increase. The effect is positive and significant for cars priced below $\$ 36,000$ and becomes nonsignificant for cars above it. Panel B indicates that the opposite happens with emotional content: its effect is more prominent for more expensive cars. The effect is nonsignificant for cars priced below $\$ 16,000$ and positive and significant for cars above this price level. Panels C and D show the impact of informational and emotional content for cars at different quality levels. Panel $\mathrm{C}$ indicates that the impact of informational content decreases with car quality: positive and significant for cars with quality ratings below 3.7 but nonsignificant for those with higher quality ratings. Finally, in Panel D, the impact of emotional content is positive, regardless of the car's quality rating.

The point estimates of the effects in Figure 3 also imply that, for low-price and low-quality cars, an increase in informational content leads to a higher increase in advertising elasticity than an increase in emotional content. In turn, for high-price and high-quality cars, an increase in emotional content leads to a higher increase in advertising elasticity than an increase in informational content. Thus, to improve the sales elasticity to advertising (and thus sales), the managers of low-price and low-quality cars should prioritize informational cues (instead of emotional cues), whereas the managers of high-price and high-quality cars should emphasize emotional cues (instead of informational cues).

\section{Additional Determinants of Online Search and Sales}

We do not find significant effects of price on online search or sales $\left(\delta_{1}^{\mathrm{OS}}=.055, p>.1 ; \delta_{1}^{\mathrm{S}}=-1.365, p>.1\right)$. These nonsignificant results might be due to the limited variation of the price variable over time.

Competitive advertising reduces the level of online search for the focal car $\left(\delta_{2}^{\mathrm{OS}}=-.152, p<.01\right)$, in line with the idea that brand advertising leads to brand-related online search rather than category search (Joo, Wilbur, and Zhu 2016). However, we do not find a significant effect of competitive advertising on sales $\left(\delta_{2}^{\mathrm{S}}=.042, p>.1\right)$.

The volume of online search is higher during the first six months after the introduction of a car $\left(\delta_{3}^{\mathrm{OS}}=.421, p<.01\right)$, which signals increased consumer interest in the months following a product's introduction. However, sales are lower during the first six months after introduction $\left(\delta_{3}^{\mathrm{S}}=-.258, p<\right.$ .01 ), possibly due to limited product distribution. The volume 
of online search does not change when the manufacturer stops producing the car $\left(\delta_{4}^{\mathrm{OS}}=.107, p>.1\right)$, whereas sales decrease in this situation, possibly due to supply constraints $\left(\delta_{4}^{\mathrm{S}}=\right.$ $-2.652, p<.01)$. We do not find a significant effect of the consumer sentiment index on the volume of online search $\left(\delta_{5}^{\text {OS }}\right.$ $=-.151, p>.1)$ or on sales $\left(\delta_{5}^{\mathrm{S}}=-.051, p>.1\right)$.

Competitive sales have a positive effect on sales $\left(\delta_{6}^{\mathrm{S}}=\right.$ $.675, p<.01$ ), suggesting that individual car sales fluctuate in synchrony with sales in the category. We do not find a significant relationship between online search and the total volume of online search in the category $\left(\delta_{6}^{\mathrm{OS}}=.017, p>\right.$ .1). In addition, we do not find significant relationships between miles per dollar and car sales $\left(\delta_{7}^{\mathrm{S}}=.049, p>.1\right)$ and between the gasoline price and online search $\left(\delta_{7}^{\mathrm{OS}}=.046\right.$, $p>.1)$.

Finally, we find a positive two-way interaction between price and informational content in the sales equation, implying that cars with ads that include more information have a smaller (in magnitude) price elasticity. This is in line with the rationale that differentiated products are more likely to convey information regarding their differentiating characteristics, which leads to a smaller (in magnitude) price elasticity. In the sales equation, we also find a negative two-way interaction between quality and emotional content, meaning that the positive impact of quality on sales is smaller for cars using higher levels of emotional advertising.

\section{Predictive Performance}

To assess whether ad content and online search increase the predictive performance of the sales model, we estimate the sales models in Table 4 without correcting for endogeneity (Ebbes, Papies, and Van Heerde 2011). We use data from the last six months as a holdout sample. The results show that the mean absolute percentage error (MAPE) of the full model is, respectively, $13.8 \%$ and $13 \%$ lower than the MAPE of models that do not include online search and ad content. Moreover, the MAPE of the full model is $17.1 \%$ lower than the MAPE of a model that does not include either the volume of online search or ad content.

\section{Robustness Checks}

We estimate 17 additional model specifications to assess the stability of our results. We calibrate models that that do not account for endogeneity, control for endogeneity using control functions, assume different carryover values for the stock variables, use a different specification for the stock variables, estimate Equations 3 and 5 simultaneously, and include several other control variables and additional operationalizations for quality. We also estimate the model splitting the sample in different price and quality tiers and run the models without the three-way interactions. Web Appendix F contains the details of the analyses and the results. Most of the results hold across the different robustness checks, which provides support for the reliability of our findings.

\section{Discussion}

Advertising content can be used strategically to increase online search and sales. Increasing online search is an important objective, because consumers who learn about products are more likely to buy and talk about them. Increasing sales has a direct impact on firm profitability. We thus consider the differential impact of ad content on both online search and sales. Moreover, we examine how this impact is moderated by product positioning, to help managers strategically adapt their ad content to the positioning of their products and their marketing objectives. We provide a summary of our findings and their managerial implications in Table 6.

\section{Managerial Implications}

Our results are useful for practitioners interested in increasing the volume of online search. Ads with high levels of emotional content are more effective for generating online search than are ads with low levels of emotional content. Furthermore, the amount of information in an ad does not determine its effectiveness for generating online search. These results hold, regardless of the positioning of the car. Thus, we recommend that advertisers design ads with more emotional content when their objective is to increase online search.

Our analysis of the total impact of advertising on sales also offers insights for advertisers interested in increasing sales. Managers of high-end cars should design ads with high levels of emotional content to increase the sales effectiveness of their advertising campaigns (with the advantage that these ads will also generate additional online search). Yet for low-price and low-quality cars, increases in informational content are more effective at generating sales than increases in emotional content. Thus, the managers of these products need to decide whether they want to use high levels of emotional content to increase online search, at the expense of sales, or use high levels of informational content to increase sales, at the expense of online search.

A sales model containing ad content and online search explains and predicts outcomes better than models that do not contain these variables. This finding is important for brand analysts and data providers. Brand analysts may calibrate models using the content of past campaigns and use the results to forecast the effectiveness of new campaigns. These forecasts could help firms design ads that will increase the returns on their advertising. Noting that ad content is useful to firms, data providers (e.g., Kantar, Nielsen) might code ad content (e.g., according to the extent to which ads contain informative or emotional cues) and sell the data to firms. Our results further suggest that a panel data model for sales that omits online search fails to capture the heterogeneity in the indirect effect of advertising. Such a model underestimates advertising effectiveness for cheap cars. Therefore, adding online search to a 
Table 6. Overview of Findings and Managerial Implications in the U.S. Car Market.

Online Search and Ad Content

- Increases in emotional content increase the impact of advertising on online search.

\section{Sales and Ad Content}

- Increases in informational and emotional content increase the impact of advertising on sales.

- Increases in informational content are more effective for low-price and low-quality cars than for high-price and high-quality cars.

- Increases in emotional content are more effective for high-price than for low-price cars.

- For low-price and low-quality cars, an increase in informational content leads to more sales than the same increase in emotional content.

- For high-price and high-quality cars, an increase in emotional content leads to more sales than the same increase in informational content.

\section{Sales and Online Search}

- The impact of online search on sales is stronger for low-price than for high-price cars.

- The previous effect implies that the indirect impact of advertising on sales (through online search) is higher for low-price than for highprice cars.

\section{Modeling Sales}

- A sales model that contains online search and ad content explains and predicts sales better than a model that does not include these variables.

- A panel data model for sales that does not include online search as a predictor fails to capture the heterogeneity in the indirect impact of advertising and yields biased advertising elasticities.
- Car managers should prioritize emotional content (instead of informational content) in their ads if their objective is to encourage consumers to search for information about their products.

- The managers of high-price and high-quality cars should design ads with high levels of emotional content to increase the sales effectiveness of their advertising campaigns.

- The managers of low-price and low-quality cars need to decide whether they want to use high levels of emotional content to increase online search, at the expense of sales, or use high levels of informational content to increase sales, at the expense of online search.

- Using advertising to encourage consumers to search online is more valuable for low-price cars than for high-price cars.

- Adding online search and advertising content into sales models can help analysts generate better sales forecasts and obtain more accurate advertising elasticities for the products in a brand portfolio. panel data model for sales could help analysts obtain more accurate advertising elasticities.

\section{Limitations and Future Research}

This study is subject to several limitations. Our empirical analysis is based on the automotive industry. Therefore, caution must be exercised in extrapolating our results to other contexts. For instance, car consumers are likely to be highly involved in the purchase decision because cars are complex and expensive, and consumer involvement might moderate the impact of advertising content. Future research could explore if our findings also hold for low-involvement product categories.

In addition, we considered only two dimensions of advertising content. Continued research might study the effectiveness of other advertising typologies (e.g., focused on price or brand building) or other advertising elements (e.g., visual, auditory). We also assume that the advertising carryover does not depend on the number of informational and emotional cues in ads. The literature suggests that the effects of informational content wears out faster than the effects of emotional content
(Bruce 2008; MacInnis, Rao and Weiss 2002), so we would expect informational (emotional) content to reduce (increase) the carryover effect of advertising. Future research could develop a methodology to assess the impact of ad content on the carryover effects of advertising.

Our results show that price and quality do not moderate the effect of ad content in the search stage. One reason could be that a significant proportion of consumers is not aware of these product characteristics before engaging in online search. These nonsignificant effects may be specific to the car industry, so future research could investigate if they hold in other industries. Future studies could also replicate our study in product categories in which online search is not popular as it is in the automotive industry and assess whether adding online search data helps to improve the sales forecasts.

Finally, much remains to be examined in the area of advertising content. Future studies could also explore the impact of ad content on other stages of the funnel. In addition, future studies could broaden the scope of this study using new language and image processing technologies to code the content of a large numbers of ads. We hope that future studies will help 
deepen our understanding of the effects of ad content across stages of the purchase funnel.

\section{Associate Editor}

Harald van Heerde

\section{Declaration of Conflicting Interests}

The author(s) declared no potential conflicts of interest with respect to the research, authorship, and/or publication of this article.

\section{Funding}

The author(s) received no financial support for the research, authorship, and/or publication of this article.

\section{References}

Aaker, David A. and J. Gary Shansby (1982), "Positioning Your Product," Business Horizons, 25 (3), 56-62.

Ackerberg, Daniel A. (2001), "Empirically Distinguishing Informative and Prestige Effects of Advertising," RAND Journal of Economics, 32 (2), 316-33.

Amaldoss, Wilfred and Sanjay Jain (2005), "Pricing of Conspicuous Goods: A Competitive Analysis of Social Effects," Journal of Marketing Research, 42 (1), 30-42.

American Auto Council (2018), "State of the U.S. Automotive Industry," (accessed October 6, 2020), http://www.americanauto council.org/sites/aapc2016/files/2018\%20Economic\%20Contribu tion\%20Report.pdf.

Anderson, Simon P. and Régis Renault (2006), "Advertising Content," American Economic Review, 96 (1), 93-113.

Bagozzi, Richard P., Mahesh Gopinath, and Prashanth U. Nyer (1999), "The Role of Emotions in Marketing," Journal of the Academy of Marketing Science, 27 (2), 184-206.

Balachander, Subramanian, Yan Liu, and Axel Stock (2009), “An Empirical Analysis of Scarcity Strategies in the Automobile Industry," Management Science, 55 (10), 1623-37.

Bass, Frank M., Norris Bruce, Sumit Majumdar, and B.P.S. Murthi (2007), "Wearout Effects of Different Advertising Themes: A Dynamic Bayesian Model of the Advertising-Sales Relationship," Marketing Science, 26 (2), 179-95.

Batra, Rajeev and Kevin L. Keller (2016), "Integrating Marketing Communications: New Findings, New Lessons, and New Ideas," Journal of Marketing, 80 (6), 122-45.

Batra, Rajeev and Michael L. Ray (1985), "How Advertising Works at Contact," in Psychological Processes and Advertising Effects, Linda F. Alwitt and Andrew A. Mitchell, eds. Hillsdale, NJ: Lawrence Erlbaum Associates, 13-44.

Becker, Maren, Nico Wiegand, and Werner J. Reinartz (2019), "Does It Pay to Be Real? Understanding Authenticity in TV Advertising," Journal of Marketing, 83 (1), 24-50.

Bertrand, Marianne, Dean Karlan, Sendhil Mullainathan, Eldar Shafir, and Jonathan Zinman (2010), "What's Advertising Content Worth? Evidence from a Consumer Credit Marketing Field Experiment," Quarterly Journal of Economics, 125 (1), 263-306.
Bloch, Peter H., Daniel L. Sherrell, and Nancy M. Ridgway (1986), "Consumer Search: An Extended Framework," Journal of Consumer Research, 13 (1), 119-26.

Bronnenberg, Bart J. and Luc Wathieu (1996), “Asymmetric Promotion Effects and Brand Positioning," Marketing Science, 15 (4), 379-94.

Bruce, Norris I. (2008), "Pooling and Dynamic Forgetting Effects in Multitheme Advertising: Tracking the Advertising Sales Relationship with Particle Filters," Marketing Science, 27 (4), 659-73.

Bruce, Norris I., Maren Becker, and Werner Reinartz (2020). "Communicating Brands in Television Advertising," Journal of Marketing Research, 57 (2), 236-56.

Burmester, Alexa B., Jan U. Becker, Harald J. van Heerde, and Michel Clement (2015), "The Impact of Pre- and Post-Launch Publicity and Advertising on New Product Sales," International Journal of Research in Marketing, 32 (4), 408-17.

Chan, Tat Y., Chunhua Wu, and Ying Xie (2011), "Measuring the Lifetime Value of Customers Acquired from Google Search Advertising," Marketing Science, 30 (5), 837-50.

Chandrasekaran, Deepa, Raji Srinivasan, and Debika Sihi (2018), "Effects of Offline Ad Content on Online Brand Search: Insights from Super Bowl Advertising," Journal of the Academy of Marketing Science, 46 (3), 403-30.

Chandy, Rajesh K., Gerard J. Tellis, Deborah J. MacInnis, and Pattana Thaivanich (2001), "What to Say When: Advertising Appeals in Evolving Markets," Journal of Marketing Research, 38 (4), 399-414.

Choi, Hyunyoung and Hal Varian (2012), "Predicting the Present with Google Trends," Economic Record, 88, 2-9.

Danaher, Peter J., André Bonfrer, and Sanjay Dhar (2008), "The Effect of Competitive Advertising Interference on Sales for Packaged Goods," Journal of Marketing Research, 45 (2), 211-25.

Danaher, Peter J. and Harald J. van Heerde (2018), "Delusion in Attribution: Caveats in Using Attribution for Multimedia Budget Allocation," Journal of Marketing Research, 55 (5), $667-85$.

Dinner, Isaac M., Harald J. van Heerde, and Scott A. Neslin (2014), "Driving Online and Offline Sales: The Cross-Channel Effects of Traditional, Online Display, and Paid Search Advertising," Journal of Marketing Research, 51 (5), 527-45.

Du, Rex Y., Linli Xu, and Kenneth C. Wilbur (2019), "Immediate Responses of Online Brand Search and Price Search to TV Ads," Journal of Marketing, 83 (4), 81-100.

Ebbes, Peter, Dominik Papies, and Harald J. van Heerde (2011), "The Sense and Non-Sense of Holdout Sample Validation in the Presence of Endogeneity," Marketing Science, 30 (6), 1115-22.

Edelman, David C. (2010), "Branding in the Digital Age," Harvard Business Review, 88 (12), 62-69.

Geuens, Maggie, Patrick De Pelsmacker, and Tine Faseur (2011), "Emotional Advertising: Revisiting the Role of Product Category," Journal of Business Research, 64 (4), 418-26.

Ghosh, Mrinal, Shantanu Dutta, and Stefan Stremersch (2006), "Customizing Complex Products: When Should the Vendor Take Control?" Journal of Marketing Research, 43 (4), 664-79.

Gopinath, Shyam, Jacquelyn S. Thomas, and Lakshman Krishnamurthi (2014), "Investigating the Relationship Between 
the Content of Online Word of Mouth, Advertising, and Brand Performance," Marketing Science, 33 (2), 241-58.

Gustafson, Sven (2018), "How to Use the Internet to Shop for Your New Car," Autoblog (May 7), https://www.autoblog. com/2017/12/06/how-to-use-internet-to-shop-compare-researchnew-car/.

Haans, Hans, Neomie Raassens, and Roel van Hout (2013), "Search Engine Advertisements: The Impact of Advertising Statements on Click-Through and Conversion Rates," Marketing Letters, 24 (2), 151-63.

Hartnett, Nicole, Rachel Kennedy, Byron Sharp, and Luke Greenacre (2016), "Creative That Sells: How Advertising Execution Affects Sales," Journal of Advertising, 45 (1), 102-12.

Heath, Robert G. and Horst Stipp (2011), “The Secret of Television's Success: Emotional Content or Rational Information? After Fifty Years the Debate Continues," Journal of Advertising Research, 51 (1), 112-23.

Hooley, Graham, Amanda Broderick, and Kristian Möller (1998), "Competitive Positioning and the Resource-Based View of the Firm," Journal of Strategic Marketing, 6 (2), 97-116.

Hu, Ye, Rex Y. Du, and Sina Damangir (2014), "Decomposing the Impact of Advertising: Augmenting Sales with Online Search Data," Journal of Marketing Research, 51 (3), 300-319.

Joo, Mingyu, Kenneth C. Wilbur, Bo Cowgill, and Yi Zhu (2014), "Television Advertising and Online Search," Management Science, 60 (1), 56-73.

Joo, Mingyu, Kenneth C. Wilbur, and Yi Zhu (2016), "Effects of TV Advertising on Keyword Search," International Journal of Research in Marketing, 33 (3), 508-23.

Kalish, Shlomo (1985), “A New Product Adoption Model with Price, Advertising, and Uncertainty," Management Science, 31 (12), 1569-85.

Kopalle, Praveen K., Robert J. Fisher, Bharat L. Sud, and Kersi D. Antia (2017), "The Effects of Advertised Quality Emphasis and Objective Quality on Sales," Journal of Marketing, 81 (2), 114-26.

Krinsky, Itzhak and A. Leslie Robb (1986), "On Approximating the Statistical Properties of Elasticities," Review of Economics and Statistics, 68 (3), 715-19.

Lemon, Katherine N. and Stephen M. Nowlis (2002), "Developing Synergies between Promotions and Brands in Different Price-Quality Tiers," Journal of Marketing Research, 39 (2), 171-85.

Liaukonyte, Jura, Thales Teixeira, and Kenneth C. Wilbur (2015), "Television Advertising and Online Shopping," Marketing Science, 34 (3), 311-30.

Luan, Y. Jackie and K. Sudhir (2010), "Forecasting Marketing-Mix Responsiveness for New Products," Journal of Marketing Research, 47 (3), 444-57.

MacInnis, Deborah J., Ambar G. Rao, and Allen M. Weiss (2002), “Assessing When Increased Media Weight of Real-World Advertisements Helps Sales,” Journal of Marketing Research, 39 (4), 391-407.
Mayzlin, Dina and Jiwoong Shin (2011), "Uninformative Advertising as an Invitation to Search," Marketing Science, 30 (4), 666-85.

Mehta, Nitin, Xinlei Chen, and Om Narasimhan (2008), "Informing, Transforming, and Persuading: Disentangling the Multiple Effects of Advertising on Brand Choice Decisions," Marketing Science, 27 (3), 334-55.

Moorthy, K. Sridhar, Brian T. Ratchford, and Debabrata Talukdar (1997), "Consumer Information Search Revisited: Theory and Empirical Analysis," Journal of Consumer Research, 23 (4), 263-77.

Muehling, Darrel D. and Michelle McCann (1993), "Attitude Toward the Ad: A Review," Journal of Current Issues and Research in Advertising, 15 (2), 25-58.

Murray, Keith B. (1991), "A Test of Services Marketing Theory: Consumer Information Acquisition Activities," Journal of Marketing, 55 (1), 10-25.

Nowlis, Stephen M. and Itamar Simonson (1996), "The Effect of New Product Features on Brand Choice," Journal of Marketing Research, 33 (1), 36-46.

Olson, Jerry C. (1977), "Price as an Informational Cue: Effects on Product Evaluations," in Consumer and Industrial Buying Behavior, Jagdish Sheth, Arch G. Woodside, and Peter D. Bennett, eds. New York: North-Holland, 267-86.

Papies, Dominik, Peter Ebbes, and Harald J. van Heerde (2017), "Addressing Endogeneity in Marketing Models," in Advanced Methods in Modeling Markets, Peter S.H. Leeflang, Jaap E. Wieringa, Tammo H.A. Bijmolt, and Koen H. Pauwels, eds. Cham, Switzerland: Springer International Series in Quantitative Marketing, 581-630.

Park, Sungho and Sachin Gupta (2012), "Handling Endogenous Regressors by Joint Estimation Using Copulas," Marketing Science, 31 (4), 567-86.

Pham, Michel T. (1998), "Representativeness, Relevance, and the Use of Feelings in Decision Making," Journal of Consumer Research, 25 (2), 144-59.

Pham, Michel T. (2004), "The Logic of Feeling," Journal of Consumer Psychology, 14 (4), 360-69.

Pham, Michel T., Maggie Geuens, and Patrick De Pelsmacker (2013), "The Influence of Ad-Evoked Feelings on Brand Evaluations: Empirical Generalizations from Consumer Responses to More Than 1000 TV Commercials," International Journal of Research in Marketing, 30 (4), 383-94.

Puto, Christopher P. and William D. Wells (1984), "Informational and Transformational Advertising: The Differential Effects of Time," in Advances in Consumer Research, Vol. 11, Thomas C. Kinnear, ed. Provo, UT: Association for Consumer Research, 638-43.

Rust, Roland T., J. Jeffrey Inman, Jianmin Jia, and Anthony Zahorik (1999), "What You Don't Know About Customer-Perceived Quality: The Role of Customer Expectation Distributions," Marketing Science, 18 (1), 77-92.

Sethuraman, Raj, Gerard J. Tellis, and Richard A. Briesch (2011), "How Well Does Advertising Work? Generalizations from MetaAnalysis of Brand Advertising Elasticities," Journal of Marketing Research, 48 (3), 457-71. 
Spiller, Stephen A., Gavan J. Fitzsimons, John G. Lynch, and Gary H. McClelland (2013), "Spotlights, Floodlights, and the Magic Number Zero: Simple Effects Tests in Moderated Regression," Journal of Marketing Research, 50 (2), 277-88.

Statista (2020a), "Global Television Advertising Revenue from 2018 to 2022," (accessed September 7, 2020), https:// www.statista.com/statistics/237803/global-tv-advertisingrevenue/.

Statista (2020b), "U.S. Motor Vehicle and Parts Manufacturing Gross Output from 2005 to 2018," (accessed April 15, 2020), https:// www.statista.com/statistics/258075/us-motor-vehicle-and-partsmanufacturing-gross-output/.

Stewart, David W. and David H. Furse (1986), Effective Television Advertising: A Study of 1000 Commercials. Lexington, MA: Lexington Books.
Stewart, David W. and Scott Koslow (1989), "Executional Factors and Advertising Effectiveness: A Replication," Journal of Advertising, 18 (3), 21-32.

Tellis, Gerard J. and Birger Wernerfelt (1987), "Competitive Price and Quality Under Asymmetric Information," Marketing Science, 6 (3), 240-53.

Thompson, Derek (2011), “Thinking vs. Feeling: The Psychology of Advertising," The Atlantic (October 27), http://www.theatlantic. com/business/archive/2011/10/thinking-vs-feeling-the-psychol ogy-of-advertising/247466/

Wu, Lifang (2010), "Managing Design Quality and Conformance Quality: Models and insights," Total Quality Management, 21 (4), 383-89.

Zigmond, Dan and Horst Stipp (2010), “Assessing a New Advertising Effect: Measurement of the Impact of Television Commercials on Internet Search Queries," Journal of Advertising Research, 50 (2), $162-68$. 